\title{
Dopamine, Alpha-Synuclein, and Mitochondrial Dysfunctions in Parkinsonian Eyes
}

\author{
Alessia Indrieri1,2*, Rocco Pizzarelli3 ${ }^{3}$,Brunella Franco ${ }^{1,4}$ and Elvira De Leonibus ${ }^{1,5 *}$ \\ ${ }^{1}$ Telethon Institute of Genetics and Medicine, Pozzuoli, Italy, ${ }^{2}$ Institute for Genetic and Biomedical Research, National \\ Research Council, Milan, Italy, ${ }^{3}$ Center for Life Nanoscience, Istituto Italiano di Tecnologia, Rome, Italy, ${ }^{4}$ Medical Genetics, \\ Department of Translational Medical Science, University of Naples "Federico II", Naples, Italy, ${ }^{5}$ Institute of Biochemistry \\ and Cellular Biology, National Research Council, Rome, Italy
}

OPEN ACCESS

Edited by:

Monica Liliana Acosta, The University of Auckland,

New Zealand

Reviewed by:

Arianna Bellucci,

University of Brescia, Italy

Nicola B. Mercuri,

University of Rome Tor Vergata, Italy

*Correspondence:

Alessia Indrieri

indrieri@tigem.it

Elvira De Leonibus

elvira.deleonibus@cnr.it

Specialty section:

This article was submitted to

Neurodegeneration,

a section of the journal

Frontiers in Neuroscience

Received: 29 May 2020

Accepted: 22 September 2020

Published: 19 October 2020

Citation:

Indrieri A, Pizzarelli R, Franco $B$ and De Leonibus $E$ (2020) Dopamine, Alpha-Synuclein, and Mitochondrial Dysfunctions in Parkinsonian Eyes.

Front. Neurosci. 14:567129.

doi: 10.3389/fnins.2020.567129
Parkinson's disease $(\mathrm{PD})$ is characterized by motor dysfunctions including bradykinesia, tremor at rest and motor instability. These symptoms are associated with the progressive degeneration of dopaminergic neurons originating in the substantia nigra pars compacta and projecting to the corpus striatum, and by accumulation of cytoplasmic inclusions mainly consisting of aggregated alpha-synuclein, called Lewy bodies. PD is a complex, multifactorial disorder and its pathogenesis involves multiple pathways and mechanisms such as $\alpha$-synuclein proteostasis, mitochondrial function, oxidative stress, calcium homeostasis, axonal transport, and neuroinflammation. Motor symptoms manifest when there is already an extensive dopamine denervation. There is therefore an urgent need for early biomarkers to apply disease-modifying therapeutic strategies. Visual defects and retinal abnormalities, including decreased visual acuity, abnormal spatial contrast sensitivity, color vision defects, or deficits in more complex visual tasks are present in the majority of PD patients. They are being considered for early diagnosis together with retinal imaging techniques are being considered as non-invasive biomarkers for PD. Dopaminergic cells can be found in the retina in a subpopulation of amacrine cells; however, the molecular mechanisms leading to visual deficits observed in PD patients are still largely unknown. This review provides a comprehensive analysis of the retinal abnormalities observed in PD patients and animal models and of the molecular mechanisms underlying neurodegeneration in parkinsonian eyes. We will review the role of $\alpha$-synuclein aggregates in the retina pathology and/or in the onset of visual symptoms in PD suggesting that $\alpha$-synuclein aggregates are harmful for the retina as well as for the brain. Moreover, we will summarize experimental evidence suggesting that the optic nerve pathology observed in PD resembles that seen in mitochondrial optic neuropathies highlighting the possible involvement of mitochondrial abnormalities in the development of PD visual defects. We finally propose that the eye may be considered as a complementary experimental model to identify possible novel disease' pathways or to test novel therapeutic approaches for PD.

Keywords: Parkinson' disease, retina, mitochondria, visual dysfunctions, alpha-synuclein, dopamine, parkinsonism, optic neuropathies 


\section{INTRODUCTION}

Parkinson's disease (PD) represents the second most common neurodegenerative disorder after Alzheimer's disease. The prevalence of this condition in industrialized countries is generally estimated at $1 \%$ in people over 60 years of age representing an important burden for health systems considering that to date treatment options are mostly symptomatic (de Lau and Breteler, 2006; Kalia and Lang, 2015; Rodriguez-Blazquez et al., 2015). PD is a complex neurodegenerative disorder and the etiology of the disease is unknown in most patients. Risk factors include age, male gender and some environmental factors. Moreover, different genetic causes have been identified and both rare and common genetic variants contribute to disease risk, onset, and progression. To date, mutations in more than 20 genes, most of which are highly penetrant and often cause early onset or atypical symptoms, have been associated with the disease (reviewed in Puschmann, 2017; Deng et al., 2018; Blauwendraat et al., 2019) (Table 1).

Although genetic forms of PD represent a small fraction of all cases, they have provided important clues to the neuropathology of PD defining crucial underlining pathways such as $\alpha$-synuclein ( $\alpha$-Syn) proteostasis, mitochondrial function, oxidative stress, calcium homeostasis, axonal transport, and neuroinflammation. Of note, many PD mutations affect the SNCA gene that encodes $\alpha$-Syn and genes associated with mitochondrial function (Table 1).

$\mathrm{PD}$ is characterized by the death of dopamine (DA) neurons localized in the substantia nigra pars compacta (SNpc), from which neurons project to the corpus striatum and to other brain regions of the mesocorticolimbic system, and by the accumulation of cytoplasmic inclusions, called Lewy bodies, mainly consisting of aggregated $\alpha$-Syn and ubiquitin (Spillantini et al., 1997).

The loss of nigro-striatal DA function leads to the classical parkinsonian motor symptoms including bradykinesia, tremor at rest, and postural and gait instability (Kalia and Lang, 2015; Postuma et al., 2015). The relationship between $\alpha$-Syn aggregates and DA neuronal loss is the focus of several experimental studies; most of them convergently show that overexpression or mutation of the SNCA gene leads to the formation of $\alpha$ Syn aggregates (oligomers and fibrils), which induce a timedependent loss of DA neurons (Giordano et al., 2018). Lewy bodies are found not only in DA neurons, but are also present in different central nervous system (CNS) regions, and they are thought to contribute to other PD symptoms such as cognitive deficits, depression, sleep disorders, constipation, olfactory dysfunction, and visual defects (Braak et al., 2004; Mahlknecht et al., 2015), generally referred to as non-motor symptoms. Non-motor features are frequently observed in PD before the onset of the classical motor symptoms (Postuma et al., 2012). Recently, much attention has been given to these early nonmotor symptoms as they represent a potential temporal window during which disease-modifying therapies acting to prevent or delay neurodegeneration could be administered (Siderowf and Lang, 2012; Kalia and Lang, 2015). The molecular mechanisms underlying non-motor symptoms in PD are being investigated in experimental and clinical studies, and one of the most dominant views is that proposed by Braak (Guo et al., 2018). According to Braak's staging theory, this premotor or prodromal phase can precede the onset of classical parkinsonian motor symptoms by decades and it is due to the spreading of $\alpha$-Syn pathology from ventral to dorsal brain regions (Braak et al., 2003, 2004). This hypothesis is supported by experimental evidence showing that $\alpha$-Syn fibrils can spread across brain regions and more recent findings show that they can move from the gut to the brain (Challis et al., 2020). According to this hypothesis the eyes should be one of the first organs affected if fibrils spread from the nose, as previously suggested (Choudhry and Perlmuter, 2017), which would be in line with clinical and pre-clinical findings reporting specific visual symptoms in early stages of PD or dementia with Lewy bodies (DLB) (Armstrong, 2015; Himmelberg et al., 2018; Chung et al., 2019).

Among non-motor symptoms, one of the clinical manifestations present in the majority of $\mathrm{PD}$ patients is the presence of vision impairment and retinal abnormalities, including decreased visual acuity, abnormal spatial contrast sensitivity, color vision defects, or deficits in more complex visual tasks (Postuma et al., 2012; Guo et al., 2018). Moreover, accumulating experimental evidence suggests that pathological $\alpha$-Syn aggregates are present in the retina and/or visual system of PD patients and of PD animal models. In addition, phosphorylated $\alpha$-Syn accumulates in the retina as well as in the brain also at early stages, preceding the appearance of clinical signs of parkinsonism or dementia (Guo et al., 2018; Ortuno-Lizaran et al., 2018; Veys et al., 2019). Visual symptoms are probably the least invalidating symptoms in PD and DLB but they are being seriously considered as significant disease biomarkers. Given that the retina is an easy-access window to the pathological processes that are ongoing in the brain, visual tests and/or retinal imaging techniques are being developed to consider $\alpha$-Syn aggregates in the eye as noninvasive biomarkers for PD (Weil et al., 2016; Guo et al., 2018; Ortuno-Lizaran et al., 2018).

The data reporting visual and retinal abnormalities in PD patients have been extensively reviewed recently (Weil et al., 2016; Guo et al., 2018). In this review we will integrate the clinical evidence with those reported in animal models highlighting the molecular mechanisms underlying neurodegeneration in parkinsonian eyes. Moreover, we will provide evidence about molecular disease pathways that are common to PD and mitochondrial diseases. We propose the retina not only as a site for early PD biomarkers identification through non-invasive approaches, but also as a powerful model containing most of the cellular subtypes involved in PD pathology, which can be used as a complementary tool to study disease' pathways or to test novel therapeutic approaches for PD.

\section{NEURONAL SUBSTRATES OF VISUAL SYMPTOMS IN PD PATIENTS}

Ocular defects have been reported in about $80 \%$ of PD patients (Guo et al., 2018). Oculo-visual abnormalities include defects in 
TABLE 1 | Monogenic causes of Parkinson's disease.

\begin{tabular}{|c|c|c|c|c|c|}
\hline Gene & Protein & Mutation & Inheritance & Function & $\begin{array}{l}\text { Proposed disease } \\
\text { mechanism }\end{array}$ \\
\hline SNCA & $\alpha$-Synuclein & $\begin{array}{l}\text { Missense or } \\
\text { multiplication }\end{array}$ & Dominant & Presynaptic signaling and membrane trafficking. & $\begin{array}{l}\text { Gain of function or } \\
\text { overexpression }\end{array}$ \\
\hline LRRK2 & $\begin{array}{l}\text { Leucine-rich repeat serine/threonine-protein } \\
\text { kinase } 2\end{array}$ & Missense & Dominant & $\begin{array}{l}\text { Neuronal plasticity, autophagy, and vesicle trafficking. } \\
10 \% \text { located in the outer mitochondrial membrane }\end{array}$ & Gain of function \\
\hline PRKN & Parkin & $\begin{array}{l}\text { Missense, exon } \\
\text { deletion or } \\
\text { duplication }\end{array}$ & Recessive & Proteasomal degradation, mitophagy, cell death, oxidative stress & Loss of function \\
\hline PINK1 & PTEN induced kinase 1 & $\begin{array}{l}\text { Missense, } \\
\text { deletion }\end{array}$ & Recessive & Protection against mitochondrial dysfunction, mitophagy & Loss of function \\
\hline POLG & DNA polymerase subunit gamma-1 & Missense & $\begin{array}{l}\text { Dominant/ } \\
\text { recessive }\end{array}$ & Replication of mitochondrial DNA & Loss of function \\
\hline PARK7 & DJ-1 & Missense & Recessive & Cell death, oxidative stress & Loss of function \\
\hline ATP13A2 & Cation-transporting ATPase 13A2 & Missense & Recessive & Lysosome and mitochondrial maintenance & Loss of function \\
\hline GBA & Lysosomal acid glucosylceramidase & Missense & $\begin{array}{l}\text { Dominant } \\
\text { (incomplete } \\
\text { penetrance) }\end{array}$ & Ceramide formation, glycolipid metabolism, turnover of cellular membranes & $\begin{array}{l}\text { Likely loss of } \\
\text { function }\end{array}$ \\
\hline FBXO7 & F-box protein 7 & Missense & Recessive & Proteasomal degradation, mitophagy, cell death, oxidative stress & Loss of function \\
\hline PLA2G6 & Phospholipase A2 group VI & Missense & Recessive & $\begin{array}{l}\text { Phospholipid remodeling, arachidonic acid release, leukotriene and } \\
\text { prostaglandin synthesis, cell death }\end{array}$ & Loss of function \\
\hline VPS35 & Vacuolar protein sorting-associated protein 35 & Missense & Dominant & Transport of proteins from endosomes to the trans-Golgi network & Loss of function \\
\hline VPS13C & Vacuolar protein sorting-associated protein $13 \mathrm{C}$ & $\begin{array}{l}\text { Missense, } \\
\text { deletion }\end{array}$ & Recessive & $\begin{array}{l}\text { Mitochondrial function, maintenance of mitochondrial transmembrane potential, } \\
\text { mitophagy, Golgi to endosome transport }\end{array}$ & Loss of function \\
\hline SYNJ1 & Synaptojanin 1 & Missense & Recessive & $\begin{array}{l}\text { Polyphosphoinositide phosphatase involved in clathrin-coated pit and synaptic } \\
\text { vesicle dynamics }\end{array}$ & Loss of function \\
\hline DNAJC6 & Auxilin & Missense & Recessive & Clathrin-mediated endocytosis & Loss of function \\
\hline DNAJC13 & DnaJ heat shock protein family member $\mathrm{C} 13$ & Missense & Dominant & Clathrin-mediated endocytosis, post-endocytic transport & Unclear \\
\hline TMEM230 & Transmembrane protein 230 & $\begin{array}{l}\text { Missense, } \\
\text { deletion }\end{array}$ & Dominant & Trafficking and recycling of synaptic vesicles & $\begin{array}{l}\text { Likely loss of } \\
\text { function }\end{array}$ \\
\hline TWNK & Twinkle mtDNA helicase & Missense & Dominant & mtDNA replication & Loss of function \\
\hline UCHL1 & $\begin{array}{l}\text { Ubiquitin carboxyl-terminal hydrolase } \\
\text { isozyme L1 }\end{array}$ & Missense & Dominant & Processing of ubiquitin precursors and of ubiquitinated proteins & $\begin{array}{l}\text { Likely loss of } \\
\text { function }\end{array}$ \\
\hline HTRA2 & Serine protease HTRA2, mitochondrial & Missense & Recessive & Mitochondrial-dependent cell death & Unclear \\
\hline EIF4G1 & $\begin{array}{l}\text { Eukaryotic translation initiation factor } 4 \\
\text { gamma } 1\end{array}$ & Missense & Dominant & Component of the elF4F complex, translation initiation & Unclear \\
\hline GIGYF2 & GRB10-interacting GYF protein 2 & Missense & Dominant & Component of the 4EHP-GYF2 complex, repressor of translation initiation & Unclear \\
\hline $\mathrm{CHCHD2}$ & $\begin{array}{l}\text { Coiled-coil-helix-coiled-coil-helix domain } \\
\text { containing } 2 \text {, mitochondrial }\end{array}$ & Missense & Dominant & OHPHOS, mitochondrial-dependent cell death & $\begin{array}{l}\text { Likely loss of } \\
\text { function }\end{array}$ \\
\hline
\end{tabular}


primary vision such as visual acuity (Jones et al., 1992; Matsui et al., 2006; Archibald et al., 2011b), spatial contrast sensitivity (Bodis-Wollner et al., 1987; Bodis-Wollner, 2013), color vision (Price et al., 1992; Haug et al., 1994; Silva et al., 2005; Sartucci and Porciatti, 2006), eye movement (Winograd-Gurvich et al., 2006), or deficits in more complex visual tasks such as the perception of the spatial relationships between objects and visual hallucinations (Holroyd et al., 2001; Possin, 2010; Armstrong, 2011, 2015) (Table 2).

Visual defects in PD may arise also as a consequence of cortical visual area defects. Thus, they can be attributed to changes at any level of the visual pathway as well as other sensory systems and motor function (Uc et al., 2005; Castelo-Branco et al., 2009). Histopathological and electrophysiological studies in humans and in experimental models suggest, however, that there are retina-specific visual defects in $\mathrm{PD}$ occurring in early stages of the pathology.

\section{Dopamine and $\alpha$-Synuclein in the Context of Retina Cell Subtypes}

There are six types of neurons and one type of glial cells (Müller glial cells) that constitute three cellular layers in the vertebrate retina: rod and cone photoreceptors in the outer nuclear layer (ONL), horizontal, bipolar, and amacrine interneurons and Müller glial cells in the inner nuclear layer (INL), and ganglion and displaced amacrine cells in the ganglion cell layer (GCL) (Figure 1). $\alpha$-Syn aggregates have been identified in the retina of PD patients (Beach et al., 2014; Ortuno-Lizaran et al., 2018) and in particular in the GCL, INL and in the inner plexiform layer (IPL) that contains the synaptic contacts among and between bipolar, amacrine, and ganglion cells. Retinal photoreceptor cells capture light information and transmit it to RGC via bipolar and amacrine cells. Light information then arrives at the brain through the optic nerve formed by RGC axons.

Retinal cell types are connected and located according to a well-defined cytoarchitecture reflecting their functions in the transduction of visual stimuli: their heterogeneous nature makes this process rather complex from a physiological perspective (see Demb and Singer, 2015 for details). Rod photoreceptors are responsible for vision during low light conditions (scotopic vision). They contain rhodopsin, a G-Protein coupled receptor (GPCRs), as visual pigment and are particularly sensitive to light with a peak wavelength of $\sim 500$ nanometers $(\mathrm{nm})$. Cone photoreceptors are responsible for the vision during daylight (photopic vision) and are endowed with opsin as pigment. Contrary to rods, cones are involved in color perception and can be divided in three types according to the sensitivity exhibited for blue, red, and green light.

Once photoreceptors detect photons, a change in their membrane potential causes the neurotransmitter to be released onto bipolar cells (the only neuronal type spanning both the outer and inner retina) and horizontal cells. The latter are a class of inhibitory neurons fulfilling feed-back and feed-forward inhibition on both photoreceptors and bipolar cells. Downstream of bipolar cells, the electric signal is sent to RGCs whose axons form the optic nerve responsible for transmitting information to the brain. Intermingled among bipolar and RGC, amacrine cells can provide feed-forward and feed-back inhibition to both cell types by releasing $\gamma$-aminobutyric acid (GABA) and glycine. Muller cells, seeded with their bodies in the INL, are the main glial cells of the retina and support neuronal functions.

As in the brain, dopamine plays a key role also in the retina and is involved in a variety of processes such as modulation of light adaptation, color vision, retinal development, synaptic formation and transmission (Witkovsky, 2004; McMahon et al., 2014).

$\mathrm{DA}$ in the retina is synthetized in a subpopulation of amacrine cells (A18) localized in the IPL. Amacrine cells represent $\sim 35 \%$ of all cell types and they are classified based on the synthetized neurotransmitters, which mainly include glycine and GABA. Most DA amacrine cells (DACs) also synthetize GABA. DACs constitute only a small part of amacrine cells and they often co-express GABA and glycine (May et al., 2008; Roy and Field, 2019). DACs have long axon-like processes reaching the IPL, the GCL and sometimes the OPL and processes that overlap and branch forming a densely packed network of dendrites (Figure 1). Similar to what happens in the mesencephalon, DA is released in a tonic and phasic fashion and its action potential is influenced by AMPA glutamate receptor activation, GABA and glycine (Gustincich et al., 1997; Feigenspan et al., 1998). DA exerts its action through direct synaptic contacts and through volumetric diffusion. Given its long-distance and dense network it has the potential to influence the activity at different levels and on different cell subtypes in the retina (Witkovsky, 2004; Roy and Field, 2019). DA acts on five G-protein-coupled receptor subtypes grouped in D-like receptors (D1 and D5) and D2-like (D2, D3, D4) linked to the activation (D1-like) and inhibition (D2like) of cyclic-AMP (Seeman and Van Tol, 1994; Witkovsky, 2004). In the retina, similar to what has been described in the mesencephalon, DACs contain D2 auto-receptors whose activation negatively influences DA release. In Figure 1 we have schematized the position of DA receptors in the different retina subtypes, which shows a cell type specific distribution, suggesting a functional dissociation between them. DA receptor subtypes differ in their sensitivity to DA (D5 > D2 > D1) allowing a differential recruitment during the day/light cycle characterized by high/low DA synthesis and release, respectively. This observation suggested that DA levels in the eye contribute to circadian rhythms and to a shift from rod-mediated to conemediated vision (Witkovsky, 2004). DA exerts its action in both outer and inner retinal cells; a detailed description of the underlying mechanisms goes beyond the scope of this review and have been extensively and elegantly addressed previously by Witkovsky (2004). Through pharmacological experiments, including studies using neurotoxins directly injected into the eye specifically acting on DA cells, it has been shown that DA improves spatial contrast detection and amplifies the cone pathway producing a shift from rod-dominant to cone-dominant vision during daylight (Dowling and Ehinger, 1975; Savy et al., 1995; Gustincich et al., 1999). Light stimuli activate DA cells, triggering DA release (Puopolo et al., 2001; Witkovsky, 2004); $\mathrm{DA}$ through the activation of $\mathrm{D} 4 \mathrm{R}$ stimulation reduces the rod-cone communication, and through the activation of D1 
TABLE 2 | Visual abnormalities in PD patients.

\begin{tabular}{|c|c|c|c|}
\hline Visual defect & $\begin{array}{l}\text { Frequency in } \\
\text { PD patients }\end{array}$ & Onset & References \\
\hline Visual acuity & $30 \%$ & N/A & $\begin{array}{l}\text { Jones et al., 1992; Holroyd et al., 2001; Matsui et al., 2006; Archibald et al., } \\
\text { 2011a; Lin et al., 2015; Weil et al., } 2016\end{array}$ \\
\hline Contrast sensitivity & $\mathrm{N} / \mathrm{A}$ & Prodromal stage & $\begin{array}{l}\text { Kupersmith et al., 1982; Bodis-Wollner et al., 1987; Bulens et al., 1987; } \\
\text { Bodis-Wollner, 1988, 2013; Postuma et al., 2011; Stenc Bradvica et al., 2015; } \\
\text { Weil et al., } 2016\end{array}$ \\
\hline Color recognition & $30-50 \%$ & $\begin{array}{l}\text { Prodromal stage, } \\
\text { controversial }\end{array}$ & $\begin{array}{l}\text { Price et al., 1992; Buttner et al., 1994, 1995; Haug et al., 1994, 1995; Pieri } \\
\text { et al., 2000; Muller et al., 2002; Silva et al., 2005; Sartucci and Porciatti, 2006; } \\
\text { Cardoso et al., 2010; Postuma et al., 2011; Bertrand et al., 2012; Piro et al., } \\
\text { 2014; Lin et al., } 2015\end{array}$ \\
\hline Visual processing difficulties & $10-30 \%$ & Prodromal stage & Postuma et al., 2011; Lin et al., 2015; Arrigo et al., 2017; Ekker et al., 2017 \\
\hline Object perception and recognition & $70 \%$ & After motor symptoms & $\begin{array}{l}\text { Montse et al., 2001; Muller et al., 2002; Uc et al., 2005; Gullett et al., 2013; } \\
\text { Edelstyn et al., 2014; Weil et al., } 2016\end{array}$ \\
\hline Visual hallucinations & $20-40 \%$ & After motor symptoms & Fenelon et al., 2000; Diederich et al., 2005; Armstrong, 2015 \\
\hline
\end{tabular}

N/A, not available.

receptors uncouples H1-type horizontal cells; both mechanisms increasing the direct response of cones in photopic conditions. By contrast, the absence of DA favors the rod-cone conductance and shunting of the cone electrical signal (Veruki and Wassle, 1996; Puopolo et al., 2001; Witkovsky, 2004; Roy and Field, 2019). Interestingly, a mouse model where the synthesis of DA was specifically prevented in the retina was generated by conditional inactivation of the tyrosine hydroxylase $(\mathrm{TH})$ gene, which encodes the DA synthesis rate limiting enzyme. These mice showed deficits in light-adapted electroretinogram (ERG) responses, contrast sensitivity, acuity, and retinal circadian rhythms. These specific deficits could be mimicked in either DA, D1R, and D4R knock-out (KO) mice and rescued by D1R or D4R agonists (Jackson et al., 2012). In the retina of healthy individuals, the presence of endogenous $\alpha$-Syn has been described in the GCL, IPL and INL, and also in photoreceptor outer segments and their terminals in the outer plexiform layer (OPL) (Martinez-Navarrete et al., 2007; Leger et al., 2011). These data are consistent with the presence of the $\alpha$-Syn monomeric form in the cytoplasm and presynaptic nerve terminals and with its involvement in physiological functions such as synaptic plasticity, vesicle trafficking, and neurotransmission (Bendor et al., 2013).

Based on this set of experimental evidence highly specific DA-dependent vision deficits might be expected in PD patients. However, the visual impairment can be worsened by deficits related to $\alpha$-Syn pathology and/or mitochondrial related dysfunction that, although might preferentially impair DA neurons function in the initial stage of the pathology, are also harmful for other cell types leading to widespread neurodegeneration and impaired visual function.

As mentioned before, immunohistological studies on PD patients' postmortem retinas revealed the presence of $\alpha$-Syn aggregates and Lewy bodies in dispersed amacrine cells at the border of the INL and in the RGC layer, and diffuse $\alpha$-Syn depositions and Lewy neurites in the IPL (Beach et al., 2014; Bodis-Wollner et al., 2014a). Different studies reported $\alpha$-Syn aggregates/inclusions and phosphorylated $\alpha$-Syn at serine 129 (pSer129- $\alpha-S y n$ ) in the RGC, IPL and ONL but never in the outer

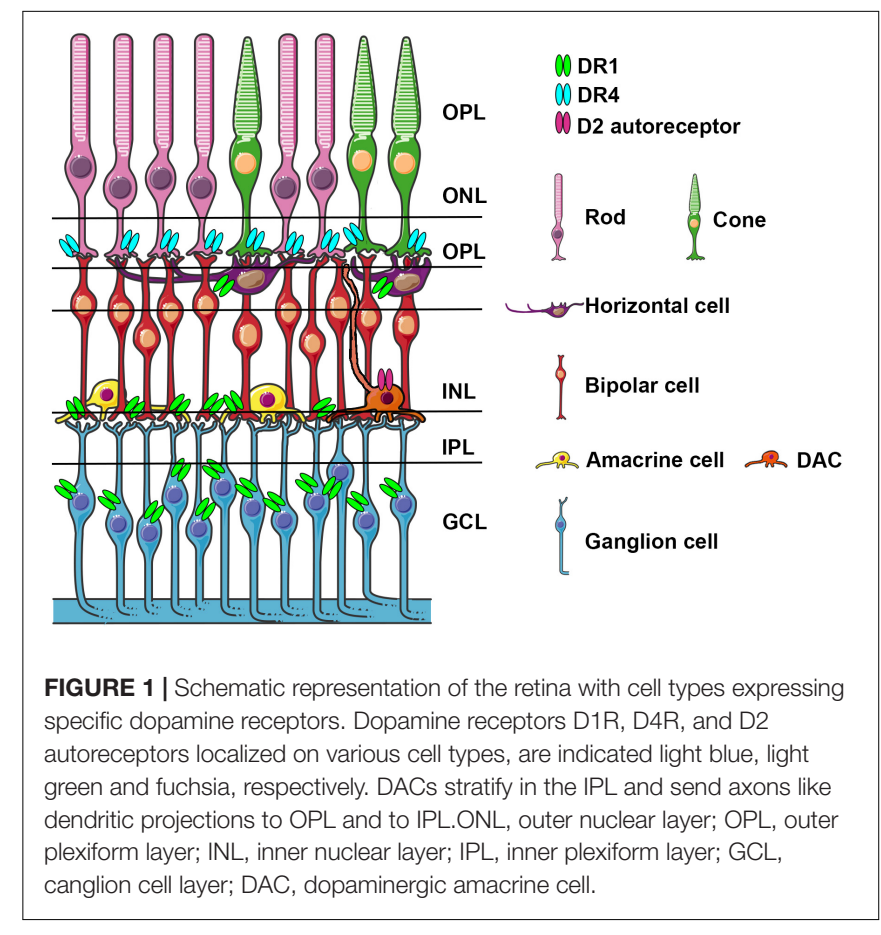

retina in $\mathrm{PD}$ patients (Figure $\mathbf{2 A}$ ). These $\alpha$-Syn formations were not present in age-matched controls where the unphosphorylated $\alpha$-Syn is seen in retinal cell layers (Beach et al., 2014; BodisWollner et al., 2014a; Ho et al., 2014; Ortuno-Lizaran et al., 2018). As already shown in the brain, abnormal pSer129- $\alpha$-Syn may play a key role in the control of $\alpha$-Syn functions, aggregation, Lewy body formation, and neurotoxicity (Oueslati, 2016).

\section{Visual Deficits in PD Patients}

Among the visual disfunctions described in PD patients, visual acuity, contrast sensitivity, and color vision impairment are more directly linked to the retinal alteration observed in PD patients showing $\alpha$-Syn aggregation, retinal neuron degeneration and reduced retinal DA levels. 
A

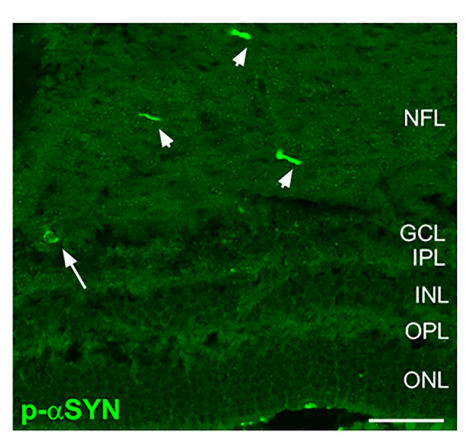

B

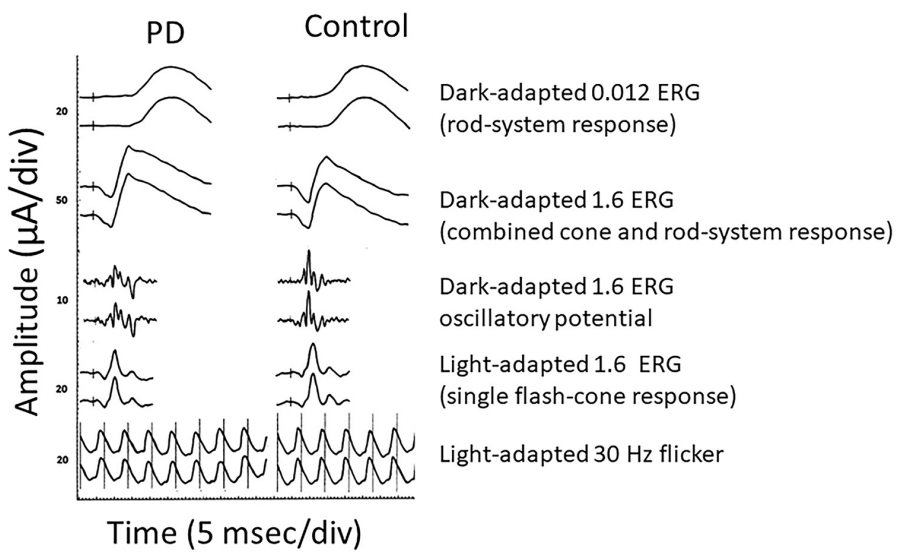

FIGURE 2 | Anatomical and functional alterations in the retina of a PD patient. (A) Retinal section from a PD patient stained for Phospho- $\alpha$-Synuclein shows the presence of aggregates both in neuronal axons (arrowheads) and soma (arrow). (B) Comparison of the scotopic a-wave, photopic b-wave and the Oscillatory Potential recorded from a control and a PD patient. Note the reduction in amplitude. Modified from Veys et al. (2019) (A) and Nowacka et al. (2015) (B) under terms of the Creative Commons Attribution 4.0 International License (http://creativecommons.org/licenses/by/4.0/).

Visual acuity refers to the ability to discern the shapes and details. Defects in this task were reported in about 30\% of PD patients and this effect is not corrected by DA (Jones et al., 1992; Matsui et al., 2006; Archibald et al., 2011b; Weil et al., 2016).

Reduction of contrast sensitivity has been found to be one of the earliest signs of PD suggesting that this defect could be used as a premotor biomarker (Guo et al., 2018). Patients with normal visual acuity but with a loss in contrast sensitivity have been described (Regan and Neima, 1984). Moreover, this deficit is progressive and correlates with $\mathrm{PD}$ disease progression (Diederich et al., 2002; Miri et al., 2016; Ridder et al., 2017). Changes in contrast sensitivity in $\mathrm{PD}$ is partly reversible by the administration of the DA precursor levodopa (L-DOPA) and have been associated with DA depletion in the retina and loss of cells in the GCL (Bulens et al., 1987; Hutton et al., 1993; Polo et al., 2016). However, the loss of contrast sensitivity seems to be dependent on the orientation of the stimulus indicating an involvement of higher visual centers (Weil et al., 2016).

Impaired color vision is one of the most prevalent visual dysfunctions observed in PD patients, correlates with the progression of the disease, and may represent a specific nonmotor feature of PD (Buttner et al., 1994; Diederich et al., 2002; Muller et al., 2002; Postuma et al., 2006; Piro et al., 2014). It has been shown that color vision abnormalities can be present several years before PD diagnosis suggesting that this defect could be an early PD biomarker (Buttner et al., 1995; Postuma et al., 2006; Diederich et al., 2010). Notably, deficits of color discrimination have also been reported in patients with rapid eye movement (REM) and sleep behavior disorder (RBD) (Postuma et al., 2006), which is considered as an early manifestation of $\alpha$ synucleinopathies (Iranzo et al., 2013). Interestingly, PD patients with leucine-rich repeat kinase (LRRK2) gene mutations show a more severe impairment of color discrimination compared with idiopathic PD patients (Marras et al., 2011). However, discordant data have been reported indicating that color vision may not be consistently impaired in early PD (Vesela et al., 2001). It has been suggested that defective color vision may represent an early sign of DA dysfunction in PD (Piro et al., 2014; Armstrong, 2015) that can be ameliorated by L-DOPA administration (Buttner et al., 1994). However, besides DA dysfunction, the loss of cells in the GCL (Polo et al., 2016), the cognitive impairment and the involvement of dysfunctional cortical areas (Brandies and Yehuda, 2008) may also be associated with this defect, therefore suggesting that color vision abnormalities in PD seem to be due to multifactorial causes.

\section{PATHOLOGICAL ALTERATIONS IN THE RETINA OF PD PATIENTS}

In recent years, the development of non-invasive studies such as imaging of the retina and electrophysiological assessments allowed the direct observation of structural and functional changes in the retina in $\mathrm{PD}$ patients.

Optical coherence tomography (OCT) allows measurements of retinal layers in vivo, providing structural information of the retina with 1-to-10 micrometer $(\mu \mathrm{m})$ resolution (Ang et al., 2018). In particular, OCT was used to analyze the peripapillary retinal nerve fiber layer (RNFL) and retinal thickness (i.e., macular volume scans). Different studies have shown a significant reduction in RNFL thickness of PD patients especially in the temporal quadrant (Inzelberg et al., 2004; Kirbas et al., 2013; La Morgia et al., 2013; Moreno-Ramos et al., 2013; Bodis-Wollner et al., 2014b; Lee et al., 2014a; Satue et al., 2016; Aydin et al., 2018; Matlach et al., 2018) that, notably, is typically affected in mitochondrial optic neuropathies ( $\mathrm{La}$ Morgia et al., 2013; Maresca et al., 2013). In contrast, only a few studies failed to find differences between PD patients and healthy controls (Aaker et al., 2010; Archibald et al., 2011a; Albrecht et al., 2012; Tsironi et al., 2012). OCT analysis 
reported pathological thinning of the RGC, IPL and INL, more evident in the foveal pit zone (Cubo et al., 2010; Shrier et al., 2012; Adam et al., 2013; Spund et al., 2013; Bodis-Wollner et al., 2014b; Lee et al., 2014b). However, also in this case, other studies failed to find significant differences in PD patients (Aaker et al., 2010; Archibald et al., 2011a; Albrecht et al., 2012). These discrepancies can be attributed to differences in disease stage/severity, and to diverse measurement protocols and OCT equipment and analysis methods.

Electrophysiology techniques such as electroretinography (ERG) and visual evoked potentials (VEP) allow the analysis of selective retinal circuits and the determination of dysfunction of specific retinal cell types.

A close electrophysiological examination of the retina has shown indeed a genuine impairment at the level of the local circuitry in PD subjects. ERG measures the electrical response evoked by a brief visual stimulus recorded from the retina. The analysis of the resulting electrical potential gives information about the function of different retinal cell types including cones, rods, photoreceptors and retinal interneurons (Creel, 1995). ERG is a very useful tool in order to obtain diagnostic information and for disease progression monitoring. Taking advantage of this technique, alterations in PD patients' retina have been described. In particular, scotopic and photopic b-wave as well as the amplitude of the photopic a-wave have been found to be reduced (Gottlob et al., 1987; Burguera et al., 1990). Interestingly, a reduction of the amplitude of b-waves in $\mathrm{PD}$ patients is present at early stages of the disease (Ikeda et al., 1994; Nowacka et al., 2015) (Figure 2B). An increase in the latency of the VEP onset is another frequent finding in PD patients (Tartaglione et al., 1987; Liu et al., 2017; He et al., 2018).

However, it is necessary to remember that by recording at the level of the visual cortex, VEP does not provide information exclusively about the retina but rather about the whole visual pathway. To date, the precise mechanisms responsible for the alterations described above are not fully understood. It has been suggested that decreased levels of DA can account (at least in part) for these abnormalities. In agreement with this suggestion, lower levels of $\mathrm{TH}$ or $\mathrm{DA}$ in the retina of PD patients have been also described (Nguyen-Legros, 1988; Harnois and Di Paolo, 1990).

Different studies have demonstrated that PD patients display ERG profiles in which the amplitude and the latency are altered as compared to control age-matched subjects (Gottlob et al., 1987; Tartaglione et al., 1987; Burguera et al., 1990; Ikeda et al., 1994). Interestingly, the ERG alterations observed in $\mathrm{PD}$ patients can be mimicked with the DA receptor D2 antagonist I-sulpiride both in humans (Stanzione et al., 1995) and monkeys (Tagliati et al., 1994). As mentioned before, D2 receptor activation mimics the low levels of DA release. Although very informative, it is necessary to stress that these studies have important limitations since they provide only descriptive observations, without information on the cellular and molecular basis underlying the observed ERG impairment. Moreover, most of these studies focused on heterogeneous groups of patients thus making it difficult to extrapolate conclusive information.
These limitations in terms of mechanistic issues are compensated by the high clinical relevance that the combination of these ophthalmic diagnostic tools (i.e., ERG, PERG, OCT) may represent for early and non-invasive diagnosis of $\mathrm{PD}$.

\section{VISUAL AND RETINAL ABNORMALITIES IN PD ANIMAL MODELS}

To date a limited number of studies has been performed on the retina of PD animal models; all these studies, however, consistently report visual and retinal abnormalities as summarized in Table 3.

Ocular abnormalities were studied in the classical neurotoxininduced rodent models generated by systemic administration or intracranial injection of drugs, such as Rotenone, 6hydroxydopamine (6-OHDA), or 1-methyl- 4-phenyl-1,2,3,6tetrahydropyridine (MPTP).

Rotenone is a naturally occurring pesticide and a potent inhibitor of the Mitochondrial Respiratory Chain (MRC) complex I and is used to model PD in animals. Rotenone-treated rats showed a decreased number of RGC and DA amacrine cells as wells as decreased thickness of the INL and ONL (Biehlmaier et al., 2007; Esteve-Rudd et al., 2011; Normando et al., 2016). These abnormalities were accompanied by a decrease in the amplitude of scotopic and photopic a- and b-waves (EsteveRudd et al., 2011). Notably, in this model, in vivo OCT analysis and detection of apoptotic retinal cells (DARC) demonstrated retinal neurodegeneration at 20-days post-rotenone injection, while degeneration of DA neurons in the SN and striatum became evident at day 60 . These data indicate that neurodegeneration occurs first in the retina and then in the brain supporting the idea that the retina can be used as a potential biomarker tissue for early diagnosis.

6-OHDA and MPTP are toxins that selectively destroy DA containing neurons and are widely used to induce PD in animal models. Unilateral injection of 6-OHDA into the substantia nigra induced a decrease in DA levels in the retina of a rat PD model (Meng et al., 2012). Abnormal PERG responses of the RGC have been observed in monkeys intravitreally injected with 6-OHDA (Bodis-Wollner and Tzelepi, 1998). Finally, intravitreal administration of 6OHDA in mice resulted in a significant decrease of DACs and impairment of visual-acuity, which was rescued by L-DOPA (Marrocco et al., 2020).

Injection of MPTP in mice and monkeys causes a reduction in the number of $\mathrm{TH}$-positive amacrine cells and in retinal dopamine levels (Tatton et al., 1990; Cuenca et al., 2005). In MPTP-injected monkeys Cuenca and collaborators also reported a decrease in $\gamma$-aminobutyric acidergic and glycinergic amacrine cells, a deterioration of AII amacrine cells exhibiting a loss of lobular appendages and dendritic processes, abnormal electrical synapses among AII cells, as well as chemical synapses between these and rod bipolar cells (Cuenca et al., 2005). Moreover, similar to PD patients, MPTP monkeys also show RNFL thinning, a decreased macula volume and foveal thickness as shown by OCT (Schneider et al., 2014). These defects resulted in abnormal PERG 
TABLE 3 | Retinal abnormalities in PD animal models.

\begin{tabular}{|c|c|c|c|c|}
\hline & Model & Biochemical and histological abnormalities & Visual defects & References \\
\hline Rotenone & Rat & $\begin{array}{l}\text { Decreased number of RGCs and DA amacrine cells. } \\
\text { Reduced thickness of INL and ONL }\end{array}$ & Decreased scotopic and photopic a- and b-waves & $\begin{array}{l}\text { Biehlmaier et al., 2007; Esteve-Rudd } \\
\text { et al., 2011; Normando et al., } 2016\end{array}$ \\
\hline \multirow[t]{3}{*}{ 6-OHDA } & Rat & Decreased dopamine level & NA & Meng et al., 2012 \\
\hline & Mouse & Decreased number of DA amacrine cells. & Decreased visual-acuity & Marrocco et al., 2020 \\
\hline & Monkey & NA & Abnormal PERG responses & Bodis-Wollner and Tzelepi, 1998 \\
\hline \multirow[t]{2}{*}{ MPTP } & Mouse & Decreased number of DA amacrine cells. & Reduction of oscillatory potentials and of b-wave & Takatsuna et al., 1992 \\
\hline & Monkey & $\begin{array}{l}\text { RNFL thinning and a decreased macula volume and foveal } \\
\text { thickness. } \\
\text { Decreased number of DA, } \gamma \text {-aminobutyric acidergic and } \\
\text { glycinergic amacrine cells. }\end{array}$ & $\begin{array}{l}\text { Abnormal PERG and ERG responses } \\
\text { Decreased visual acuity and contrast sensitivity }\end{array}$ & $\begin{array}{l}\text { Bodis-Wollner and Tzelepi, 1998; } \\
\text { Cuenca et al., } 2005\end{array}$ \\
\hline \multirow[t]{4}{*}{ alpha-synuclein } & $\begin{array}{l}\text { TgM83 (Prnp- A53T- } \\
\text { SNCA) Mouse }\end{array}$ & $\begin{array}{l}\text { Accumulation of pSer129- } \alpha \text {-Syn in the outer retina. } \\
\text { Increased microglial activation and GFAP immunoreactivity }\end{array}$ & NA & Mammadova et al., 2019 \\
\hline & Thy-1-A30P- SNCA Mouse & Accumulation of pSer129- $\alpha$-Syn in GCL, IPL, and INL. & NA & Veys et al., 2019 \\
\hline & $\begin{array}{l}\text { AAV-mediated wt hu- } \alpha \text {-Syn } \\
\text { overexpression }\end{array}$ & $\begin{array}{l}\text { Accumulation of pSer129- } \alpha \text {-Syn in GCL, IPL and INL. } \\
\text { Decreased number of DA amacrine cells and of RGC. }\end{array}$ & $\begin{array}{l}\text { Decreased b-wave in light-adapted condition. } \\
\text { Decreased visual acuity }\end{array}$ & Marrocco et al., 2020 \\
\hline & $\begin{array}{l}\alpha \text {-Syn over-expression } \\
\text { Drosophila }\end{array}$ & NA & Decrease ERG depolarization amplitude & Chouhan et al., 2016 \\
\hline LRRK2 & LRRK2-G2019S Drosophila & Neurodegeneration in the retina & Decrease in the peak-to-peak amplitude of the ERG & Hindle et al., 2013 \\
\hline DJ-1 & $\begin{array}{l}\text { DJ- } 1 \alpha^{\Delta ~} 72 \text { and } D J-1 \beta^{\Delta 93} \\
\text { Drosophila }\end{array}$ & NA & Abnormal VEP & Himmelberg et al., 2018 \\
\hline PINK-1 & $\begin{array}{l}\text { PINK } 1^{5} \\
\text { Drosophila }\end{array}$ & NA & Abnormal VEP & Himmelberg et al., 2018 \\
\hline
\end{tabular}

NA, not analyzed. 
and ERG responses and a decline in visual acuity and contrast sensitivity (Bodis-Wollner and Tzelepi, 1998).

Takatsuna and collaborators observed a reduction in the amplitude of oscillatory potentials and b-wave after intraperitonel injection of MPTP and ERG analysis 10 and 30 days after MPTP injections in C57BL/6J mice (Takatsuna et al., 1992). Primates treated both with MPTP or 6-OHDA (Ghilardi et al., 1988, 1989) showed spatial frequency-dependent abnormalities in both PERG and VEP, and L-DOPA administration was effective in rescuing the described ERG defects (Ghilardi et al., 1988, 1989; Bodis-Wollner and Tzelepi, 1998).

Besides the toxin-induced models, ocular abnormalities were also studied in animal models of PD including transgenic models overexpressing both wild-type (wt) and mutated $\alpha$-Syn, LRRK2 mutations, and knockout models of PINK-1 and DJ-1.

Mammadova et al. (2019) analyzed TgM83 transgenic mice expressing A53T human $\alpha$-Syn under the control of the mouse prion protein (Prnp) promoter and showed that $\alpha$ Syn accumulates in the inner and outer retina of transgenic mice, while phospho- $\alpha$-Syn was significantly increased in the ONL. The data highlighted a difference between this model and what has been found in PD patients' retinas where detection of pSer129- $\alpha$-Syn in the outer retina was not reported (Beach et al., 2014; Bodis-Wollner et al., 2014a; Ho et al., 2014; Ortuno-Lizaran et al., 2018). In addition, TgM83 transgenic mice showed increased microglial activation followed by increased GFAP immunoreactivity. No differences in retinal TH-positive cells were observed (Mammadova et al., 2019), however TH-positive cells were only analyzed in vertical slides which presents some limitations for a comprehensive quantification of the DACs with respect to whole mount retina analysis.

Similar to what has been observed in human PD retinas, the analysis of the (Thy-1)- hu-A30P- $\alpha$-Syn transgenic mouse showed the expression of the $\alpha$-SYN transgene in the inner retinal layers while phospho- $\alpha$-Syn was found in INL cells, in the cell bodies of the GCL, and in neurites in the IPL (Veys et al., 2019). No experiments were performed in either study to assess visual functions.

Recently, intravitreal injection of adeno-associated viral (AAV) vectors over-expressing the wt human $\alpha$-Syn (hu- $\alpha$ Syn) has been used to evaluate the effects of $\alpha$-Syn overexpression in the mouse retina (Marrocco et al., 2020). AAVhu- $\alpha$-Syn injected mice displayed a time-dependent decrease of the amplitude of light-adapted responses while those elicited in dark-adapted conditions were not affected. Similarly, overexpression of the human hu- $\alpha$-Syn in the retina of adult mice caused an impairment of the b-wave in light-adapted condition and a decreased visual acuity that was completely rescued by L-DOPA systemic administration. As for (Thy-1)-huA30P- $\alpha$-Syn transgenic mice and PD patients' retinas, pSer129$\alpha$-Syn accumulation were found in cells bodies of GCL and INL, and in the IPL neurites (Figure 3A). These results were mirrored by an early loss in the number of $\mathrm{TH}+$ amacrine cells (Figures 3B,C) that precede in time the loss of the RGCs (Marrocco et al., 2020). Notably this study demonstrated for the first time that $\alpha$-Syn overexpression in the retina leads to neurodegeneration of DA amacrine cells, causing retinal-specific defects and consequent visual impairment that resemble the human PD phenotype (Marrocco et al., 2020). These findings is even more interesting in light of very recent evidence reporting a specific reduction of the DAC number as well as of the number of their synaptic contacts with AII amacrine cells and melanopsin cells reported in the retina of PD patients (Ortuno-Lizaran et al., 2020).

The genetic component of PD had been neglected for long time but the discovery of genes associated with this disorder has stressed the importance of this aspect in the pathogenesis of the disease. Mutations found in PD patients have been inserted in Drosophila and retinal functions have been examined. Among the mutations tested, one of the most common is the LRRK2-G2019S mutation. Its impact on visual function has been assessed by ERG following a 500 millisecond (msec) stimulation with blue light. Electrophysiological experiments revealed that compared to currents recorded from controls flies, the decrease in the peak-to-peak amplitude of the ERG observed in mutated flies was age-dependent, since it was detected starting at 10 days, reaching a minimal value at 28 days (Hindle et al., 2013). At the anatomical level, this mutation induced a marked neurodegeneration in the internal structure of the retina. Interestingly, this effect is not accompanied by loss of dopaminergic neurons (Hindle et al., 2013).

More recently, a comparison of visual function among Drosophila models carrying the early-onset PD mutations $D J-1 \alpha^{\Delta} 72, D J-1 \beta^{\Delta} 93$, and PINK1 $1^{5}$ (Himmelberg et al., 2018) has been performed. In order to investigate the consequences of the above mutations on the response of neuronal populations in the retina, the authors recorded steady-state VEP (SSVEP) from the surface of the Drosophila eye following stimulation with a sequence of frequencytagged flickering stimuli. By using this experimental paradigm, the authors reported an abnormal increase in the SSVEP amplitude induced by all three mutations (Himmelberg et al., 2018). The Rh1-GAL4 driver has been used in order to achieve over-expression of the full-length $\alpha$-Syn protein in Drosophila. This manipulation was responsible for a mild decrease of ERG depolarization amplitude according to an age-dependent model reaching the strongest effect at 30 days (Chouhan et al., 2016).

\section{MOLECULAR MECHANISMS IMPLICATED IN PD VISUAL ABNORMALITIES}

Visual dysfunction in PD patients may be mainly explained by the depletion of DA due to the loss of amacrine and inner plexiform cells of the retina. Notably, changes in both contrast sensitivity and color vision are partly reversible by L-DOPA administration (Bulens et al., 1987; Hutton et al., 1993; Buttner et al., 1994). Moreover, changes in DA levels and depletion of amacrine cells lead to alterations in the receptive properties of 


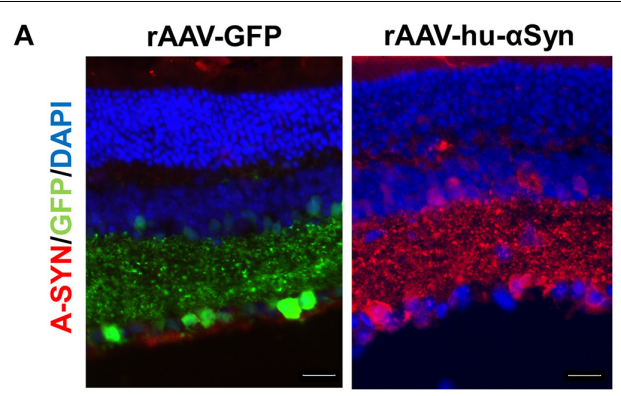

B

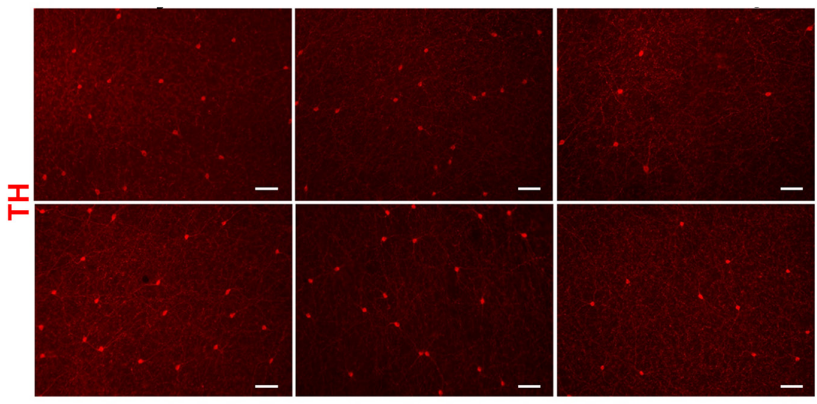

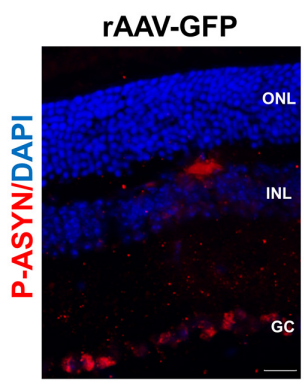

C

\section{rAAV-hu-aSyn}
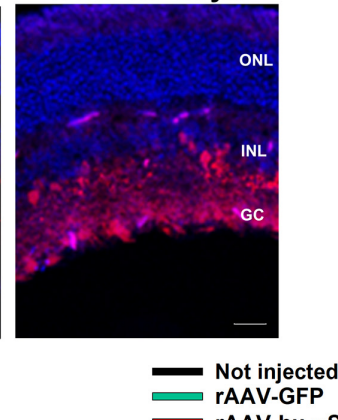

rAAV-hu- $\alpha$ Syn

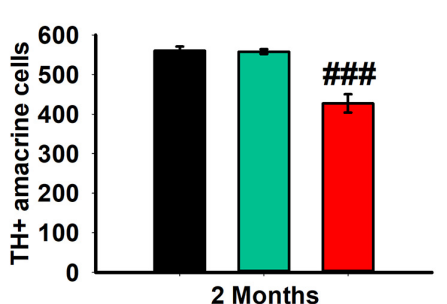

FIGURE 3 | (A) Representative immunofluorescence showing retinal sections of rAAV-hu- $\alpha$-syn injected mice and rAAV-GFP mice stained with antibody anti-hu- $\alpha$-syn (A-SYN) (red) and antibody anti-phospho $\alpha$-syn (P-ASYN). (B) Representative images of the retina whole mount anti-TH immunofluorescence on Not injected, rAAV-GFP- and rAAV-hu- $\alpha$-syn-injected mice at 2 months post-injection. (C) Number of TH-positive cells. $N \geq 5$. Data represent mean \pm SEM. \#\#\#p <0.0001 vs. rAAV-GFP. Significance was calculated by one-way ANOVA. Modified from Marrocco et al. (2020) under terms of the Creative Commons Attribution 4.0 International License (http://creativecommons.org/licenses/by/4.0/).

RGCs, which eventually results in additional dysfunction of visual processing in PD patients. Nevertheless, electrophysiological tests and structural imaging point to defects in all inner retinal layers (GCL, IPL, and INL), indicating a loss of RGCs together with the loss of the dopaminergic plexus (Cubo et al., 2010; Shrier et al., 2012; Adam et al., 2013; Spund et al., 2013; Beach et al., 2014; Bodis-Wollner et al., 2014b; Lee et al., 2014b). This is in line with the finding of $\alpha$-Syn aggregates in the GCL, IPL, and INL in the retina of both $\mathrm{PD}$ patients and animal models that may indeed represent one of the main causes of visual abnormalities in PD.

It has been shown that $\alpha$-Syn toxicity impacts multiple pathways and impairs the functions of several organelles as well as inter-organelle contacts and organelles axonal transport. Normally $\alpha$-Syn localizes to presynaptic termini and associates with synaptic vesicles (Iwai et al., 1995; Kahle et al., 2000). Different studies showed that the normal function of $\alpha$-Syn might be disrupted in synucleinopathies, resulting in impaired synapticvesicle motility and decreased synaptic-vesicle recycling-pool size (Masliah et al., 2000; Nemani et al., 2010; Choi et al., 2013; Janezic et al., 2013). Moreover, DA terminal loss, deficient DA release, reduction in dopamine re-uptake and defective DAT function have been also shown indicating that abnormal $\alpha$-Syn can disrupt dopamine turnover through different mechanisms (Masliah et al., 2000; Lundblad et al., 2012; Janezic et al., 2013; Giordano et al., 2018). On the other hand, $\alpha$-Syn toxicity also causes dysfunctions of different organelles including the endoplasmic reticulum and the Golgi, autophagy or lysosomal pathways, and mitochondria (reviewed in Wong and Krainc,
2017). Recently, an important crosstalk between $\alpha$-Syn and mitochondrial disfunctions has been described. $\alpha$-Syn toxicity can indeed directly disrupt mitochondrial homeostasis through different mechanisms (Wong and Krainc, 2017; Vasquez et al., 2020) such as deregulation of mitochondrial dynamics, including fission/fusion and mitophagy processes (Kamp et al., 2010; Choubey et al., 2011; Nakamura et al., 2011; Chen et al., 2015; Ordonez et al., 2018), as well as damage to the mitochondrial DNA (mtDNA) and impaired mitochondrial protein import (Martin et al., 2006; Di Maio et al., 2016). Moreover, $\alpha$-Syn toxicity may also induce mitochondrial dysfunction indirectly by decreasing the level of PGC-1 $\alpha$, a key player in mitochondrial biogenesis (Zheng et al., 2010; Eschbach et al., 2015).

These finding point to a pivotal role of mitochondrial dysfunction in PD pathogenesis. Notably, in a recent study it was shown that AII cells were not reduced in PD patients, but they showed the loss of mitochondria in lobular appendages, which may indicate an energetic failure, and a loss of connexin 36 , suggesting alterations in the AII coupling and in visual signal transmission from the rod pathway (Ortuno-Lizaran et al., 2020).

Moreover, mitochondrial defects can represent per se a cause of PD. The first observation involving mitochondria in PD was the discovery that MPTP-induced parkinsonian syndrome is due to MPTP-dependent inhibition of MRC complex I (Davis et al., 1979; Langston et al., 1983; Ramsay and Singer, 1986). MPTP is metabolized to MPP + by MAO-B in glial cells and selectively concentrates in dopaminergic neurons through the dopamine transporter (DAT) (Javitch et al., 1985). As we have 
seen before, most of the toxins that leads to loss of DA cells and associated parkinsonism act either as Complex I inhibitors, such as Rotenone, or lead to increased production of reactive oxygen species (ROS) such as Paraquat and 6-OHDA (Betarbet et al., 2000; Jenner, 2001; Blesa et al., 2012; Giannoccaro et al., 2017). Moreover, many genes associated with $\mathrm{PD}$ encode proteins that impact on mitochondrial function and clearance (Exner et al., 2012) (see Table 1). Lastly, bioenergetics defects and decreased activity of MRC complexes (in particular Complex I) have been found in brains and peripheral tissues of idiopathic PD patients (Chaturvedi and Flint Beal, 2013; Bose and Beal, 2016). Of note, in many cases this may be the result of genetic predisposition, possibly related to the mtDNA, considering the occurrence of mutations, deletions, and defective mtDNA maintenance with a reduction of copy number, as a major driving mechanism of $\mathrm{PD}$ (Giannoccaro et al., 2017).

Interestingly, OCT analysis in $\mathrm{PD}$ patients reported a reduction of the RNFL thickness and a significant thinning of nerve fibers entering the infero-temporal quadrants of the optic disk, consistent with the involvement of the papillo-macular bundle (Inzelberg et al., 2004; Yavas et al., 2007; Moschos et al., 2011; La Morgia et al., 2013). This pattern of axonal loss is similar to that typically seen in Leber hereditary optic neuropathy (LHON) and in dominant optic atrophy (DOA), the most frequent mitochondrial optic neuropathies, where the temporal fibers belonging to the papillo-macular bundle are specifically susceptible (Maresca et al., 2013; Yu-Wai-Man et al., 2016). Notably, both LHON and DOA are associated with MRC Complex I defects (Yu-Wai-Man et al., 2011), which is also recognized as a key feature in the pathogenesis of sporadic and genetic forms of PD (Giannoccaro et al., 2017). Moreover, DOA, LHON, and PD are also associated with altered mitochondrial dynamics. Mitochondrial network fragmentation has been described in patient-derived cells from both DOA and PD affected individuals carrying, respectively, OPA1 and PINK1/Parkin mutations (Schapira, 2008; Carelli et al., 2009; Whitworth and Pallanck, 2009). Further, deregulation of the mitochondrial quality control mechanisms and mitophagy has been documented in RGCs of OPA1 mutant mice, and represents a key factor in PD pathogenesis (White et al., 2009; Exner et al., 2012; Giannoccaro et al., 2017).

These common mechanisms can explain the similar retinal phenotype seen in patients with $\mathrm{PD}$ and those with LHON and DOA, suggesting that they might also share similar therapeutic targets. Strategies that enhanced mitophagy and mitochondrial biogenesis resulted indeed in an amelioration of the phenotype in both LHON and PD representing attractive targets for drug development (Zheng et al., 2010; Dikic and Bremm, 2014; Eschbach et al., 2015; Koentjoro et al., 2017; Indrieri et al., 2019, 2020).

\section{CONCLUSION AND FUTURE PERSPECTIVES}

Visual abnormalities together with impairment of the retinal dopaminergic system is an intriguing phenotype in PD patients and animal models. The retina, however, has long been overlooked compared to other brain regions in $\mathrm{PD}$, so the information available is rather limited. However, recent experimental evidence indicates ocular changes in $\mathrm{PD}$ as promising biomarkers in the eye that can be potentially used for early diagnosis, to track disease progression, and to evaluate novel therapeutic strategies (Guo et al., 2018; Turcano et al., 2019; Veys et al., 2019). Although the specificity and predictive value of OCT and ERG changes in PD patients are still under debate, due to overlap with normal aging and other neurological and ophthalmological diseases, a better characterization of retinal dysfunctions during neurodegenerative diseases combined with imaging of protein aggregates may indeed represent a valuable approach for early diagnosis of PD. In this respect the presence of $\alpha$-Syn deposits in the retina may have high potential for early diagnosis of PD (Veys et al., 2019; Ortuno-Lizaran et al., 2020). We thus believe that novel approaches integrating multiple biomarkers and employing novel technologies to increase diagnostic yield are needed and may be successfully applied in PD.

Moreover, due to its anatomical organization, the retina could be an ideal structure to study the molecular mechanisms underlying $\mathrm{PD}$ pathology. The retina-model of $\mathrm{PD}$ does not replace the nigrostriatal models of $\mathrm{PD}$, as it cannot recapitulate the cognitive and motor deficits as well as the complexity of the synaptic changes occurring in the mesocorticolimbic system in PD. However, it could have some advantages that combine those of in vivo brain models and in vitro cellular models. The advantage of using the retina as compared to in vitro models (including IPS or organoids) is that the animal retina recapitulates the retina of patients and the complexity of the neuronal populations present in vivo. Furthermore, in vivo studies on disease mechanisms or on drug screening on the retina allows to test vision. Differently from the standard in vivo mesencephalic models the retina in animals is accessible with non-invasive methods (such as OCT, ERG, and VEP) that allow a comprehensive analysis of the histological and functional progression of neuronal loss. This makes it particularly useful to follow the time-course of novel therapeutic strategies for months in the same subjects, which is one of the main limitations in animal models of neurodegeneration. Another important aspect is that it allows the local application of drugs, which is important for generating proof-of-concept evidence with novel pharmacological or genetic therapeutic approaches without using invasive (like intra-brain injection) and/or systemic injections that might have peripheral side effects. Therefore, the retina-model might be the first step for in vivo testing of disease modifiers. This aspect is also important for translating new therapeutic approaches to patients. Gene or pharmacological local treatments of the eyes are already at an advanced stage. There is the possibility of testing the efficacy of a treatment for a single patient by treating with local applications one single eye and evaluating it by in vivo imaging and functional tests. This would also contribute, together with studies on the 
patient IPS cells, to developing personalized therapies. For all these reasons we propose the retina as a useful complementary experimental model for the identification and study of pathways involved in the disease pathogenesis or to test novel therapeutic approaches for PD.

\section{AUTHOR CONTRIBUTIONS}

ED and AI conceived and wrote the first draft of the manuscript. $\mathrm{RP}$ wrote the electrophysiological part of the manuscript. BF edited the manuscript. All authors shaped the final version of the manuscript.

\section{REFERENCES}

Aaker, G. D., Myung, J. S., Ehrlich, J. R., Mohammed, M., Henchcliffe, C., and Kiss, S. (2010). Detection of retinal changes in Parkinson's disease with spectraldomain optical coherence tomography. Clin. Ophthalmol. 4, 1427-1432. doi: 10.2147/OPTH.S15136

Adam, C. R., Shrier, E., Ding, Y., Glazman, S., and Bodis-Wollner, I. (2013). Correlation of inner retinal thickness evaluated by spectral-domain optical coherence tomography and contrast sensitivity in Parkinson disease. J. Neuroophthalmol. 33, 137-142. doi: 10.1097/WNO.0b013e31828c4e1a

Albrecht, P., Muller, A. K., Sudmeyer, M., Ferrea, S., Ringelstein, M., Cohn, E., et al. (2012). Optical coherence tomography in parkinsonian syndromes. PLoS One 7:e34891. doi: 10.1371/journal.pone.0034891

Ang, M., Tan, A. C. S., Cheung, C. M. G., Keane, P. A., Dolz-Marco, R., Sng, C. C. A., et al. (2018). Optical coherence tomography angiography: a review of current and future clinical applications. Graefes Arch. Clin. Exp. Ophthalmol. $256,237-245$

Archibald, N. K., Clarke, M. P., Mosimann, U. P., and Burn, D. J. (2011a). Retinal thickness in Parkinson's disease. Parkinsonism Relat. Disord. 17, 431-436. doi: 10.1016/j.parkreldis.2011.03.004

Archibald, N. K., Clarke, M. P., Mosimann, U. P., and Burn, D. J. (2011b). Visual symptoms in Parkinson's disease and Parkinson's disease dementia. Mov. Disord. 26, 2387-2395. doi: $10.1002 / \mathrm{mds} .23891$

Armstrong, R. A. (2011). Visual signs and symptoms of progressive supranuclear palsy. Clin. Exp. Optom. 94, 150-160. doi: 10.1111/j.1444-0938.2010.00504.x

Armstrong, R. A. (2015). Oculo-visual dysfunction in Parkinson's disease. J. Parkinsons Dis. 5, 715-726. doi: 10.3233/JPD-150686

Arrigo, A., Calamuneri, A., Milardi, D., Mormina, E., Rania, L., Postorino, E., et al. (2017). Visual system involvement in patients with newly diagnosed Parkinson disease. Radiology 285, 885-895. doi: 10.1148/radiol.2017161732

Aydin, T. S., Umit, D., Nur, O. M., Fatih, U., Asena, K., Nefise, O. Y., et al. (2018). Optical coherence tomography findings in Parkinson's disease. Kaohsiung J. Med. Sci. 34, 166-171. doi: 10.1016/j.kjms.2017.11.006

Beach, T. G., Carew, J., Serrano, G., Adler, C. H., Shill, H. A., Sue, L. I., et al. (2014). Phosphorylated alpha-synuclein-immunoreactive retinal neuronal elements in Parkinson's disease subjects. Neurosci. Lett. 571, 34-38. doi: 10.1016/j.neulet. 2014.04.027

Bendor, J. T., Logan, T. P., and Edwards, R. H. (2013). The function of alphasynuclein. Neuron 79, 1044-1066. doi: 10.1016/j.neuron.2013.09.004

Bertrand, J. A., Bedetti, C., Postuma, R. B., Monchi, O., Genier Marchand, D., Jubault, T., et al. (2012). Color discrimination deficits in Parkinson's disease are related to cognitive impairment and white-matter alterations. Mov. Disord. 27, 1781-1788. doi: $10.1002 / \mathrm{mds} .25272$

Betarbet, R., Sherer, T. B., MacKenzie, G., Garcia-Osuna, M., Panov, A. V., and Greenamyre, J. T. (2000). Chronic systemic pesticide exposure reproduces features of Parkinson's disease. Nat. Neurosci. 3, 1301-1306. doi: 10.1038/81834

Biehlmaier, O., Alam, M., and Schmidt, W. J. (2007). A rat model of Parkinsonism shows depletion of dopamine in the retina. Neurochem. Int. 50, 189-195. doi: 10.1016/j.neuint.2006.08.001

\section{FUNDING}

This study was kindly supported by PRIN2017ENN4FY to ED, Fondazione Roche (grant Roche per la Ricerca 2018) to AI, and funding from the JointLab between Istituto Italiano di Tecnologia and CrestOptics to RP.

\section{ACKNOWLEDGMENTS}

We thank Dr. Elena Marrocco and Dr. Cathal Wilson for the critical reading of the manuscript and the Italian Telethon Foundation for continuous support.

Blauwendraat, C., Nalls, M. A., and Singleton, A. B. (2019). The genetic architecture of Parkinson's disease. Lancet Neurol. 19, 170-178. doi: 10.1016/S1474-4422(19) 30287-X

Blesa, J., Phani, S., Jackson-Lewis, V., and Przedborski, S. (2012). Classic and new animal models of Parkinson's disease. J. Biomed. Biotechnol. 2012:845618. doi: $10.1155 / 2012 / 845618$

Bodis-Wollner, I. (1988). Visual contrast sensitivity. Neurology 38, 336-337. doi: 10.1212/wnl.38.2.336

Bodis-Wollner, I. (2013). Foveal vision is impaired in Parkinson's disease. Parkinsonism Relat. Disord. 19, 1-14. doi: 10.1016/j.parkreldis.2012.07.012

Bodis-Wollner, I., Kozlowski, P. B., Glazman, S., and Miri, S. (2014a). alphasynuclein in the inner retina in Parkinson disease. Ann. Neurol. 75, 964-966. doi: 10.1002/ana.24182

Bodis-Wollner, I., Miri, S., and Glazman, S. (2014b). Venturing into the no-man's land of the retina in Parkinson's disease. Mov. Disord. 29, 15-22. doi: 10.1002/ mds. 25741

Bodis-Wollner, I., Marx, M. S., Mitra, S., Bobak, P., Mylin, L., and Yahr, M. (1987). Visual dysfunction in Parkinson's disease. Loss in spatiotemporal contrast sensitivity. Brain 110(Pt 6), 1675-1698. doi: 10.1093/brain/110.6.1675

Bodis-Wollner, I., and Tzelepi, A. (1998). The push-pull action of dopamine on spatial tuning of the monkey retina: the effects of dopaminergic deficiency and selective D1 and D2 receptor ligands on the pattern electroretinogram. Vision Res. 38, 1479-1487.

Bose, A., and Beal, M. F. (2016). Mitochondrial dysfunction in Parkinson's disease J. Neurochem. 139(Suppl. 1), 216-231. doi: 10.1111/jnc.13731

Braak, H., Del Tredici, K., Rub, U., de Vos, R. A., Jansen Steur, E. N., and Braak, E. (2003). Staging of brain pathology related to sporadic Parkinson's disease. Neurobiol. Aging 24, 197-211.

Braak, H., Ghebremedhin, E., Rub, U., Bratzke, H., and Del Tredici, K. (2004). Stages in the development of Parkinson's disease-related pathology. Cell Tissue Res. 318, 121-134.

Brandies, R., and Yehuda, S. (2008). The possible role of retinal dopaminergic system in visual performance. Neurosci. Biobehav. Rev. 32, 611-656. doi: 10. 1016/j.neubiorev.2007.09.004

Bulens, C., Meerwaldt, J. D., Van der Wildt, G. J., and Van Deursen, J. B. (1987). Effect of levodopa treatment on contrast sensitivity in Parkinson's disease. Ann. Neurol. 22, 365-369. doi: 10.1002/ana.410220313

Burguera, J. A., Vilela, C., Traba, A., Ameave, Y., and Vallet, M. (1990). [The electroretinogram and visual evoked potentials in patients with Parkinson's disease]. Arch. Neurobiol. 53, 1-7.

Buttner, T., Kuhn, W., Muller, T., Patzold, T., Heidbrink, K., and Przuntek, H. (1995). Distorted color discrimination in 'de novo' parkinsonian patients. Neurology 45, 386-387. doi: 10.1212/wnl.45.2.386

Buttner, T., Kuhn, W., Patzold, T., and Przuntek, H. (1994). L-Dopa improves colour vision in Parkinson's disease. J. Neural Transm. Park. Dis. Dement. Sect. 7, 13-19. doi: 10.1007/bf02252659

Cardoso, E. F., Fregni, F., Maia, F. M., Melo, L. M., Sato, J. R., Cruz, A. C., et al. (2010). Abnormal visual activation in Parkinson's disease patients. Mov. Disord. 25, 1590-1596. doi: $10.1002 / \mathrm{mds} .23101$ 
Carelli, V., La Morgia, C., Valentino, M. L., Barboni, P., Ross-Cisneros, F. N., and Sadun, A. A. (2009). Retinal ganglion cell neurodegeneration in mitochondrial inherited disorders. Biochim. Biophys. Acta 1787, 518-528. doi: 10.1016/j. bbabio.2009.02.024

Castelo-Branco, M., Mendes, M., Silva, F., Massano, J., Januario, G., Januario, C., et al. (2009). Motion integration deficits are independent of magnocellular impairment in Parkinson's disease. Neuropsychologia 47, 314-320. doi: 10.1016/ j.neuropsychologia.2008.09.003

Challis, C., Hori, A., Sampson, T. R., Yoo, B. B., Challis, R. C., Hamilton, A. M., et al. (2020). Gut-seeded alpha-synuclein fibrils promote gut dysfunction and brain pathology specifically in aged mice. Nat. Neurosci. 23, 327-336.

Chaturvedi, R. K., and Flint Beal, M. (2013). Mitochondrial diseases of the brain. Free Radic. Biol. Med. 63, 1-29. doi: 10.1016/j.freeradbiomed.2013.03.018

Chen, L., Xie, Z., Turkson, S., and Zhuang, X. (2015). A53T human alphasynuclein overexpression in transgenic mice induces pervasive mitochondria macroautophagy defects preceding dopamine neuron degeneration. J. Neurosci. 35, 890-905. doi: 10.1523/JNEUROSCI.0089-14.2015

Choi, B. K., Choi, M. G., Kim, J. Y., Yang, Y., Lai, Y., Kweon, D. H., et al. (2013). Large alpha-synuclein oligomers inhibit neuronal SNARE-mediated vesicle docking. Proc. Natl. Acad. Sci. U.S.A. 110, 4087-4092. doi: 10.1073/pnas. 1218424110

Choubey, V., Safiulina, D., Vaarmann, A., Cagalinec, M., Wareski, P., Kuum, M., et al. (2011). Mutant A53T alpha-synuclein induces neuronal death by increasing mitochondrial autophagy. J. Biol. Chem. 286, 10814-10824. doi: 10.1074/jbc.M110.132514

Choudhry, H., and Perlmuter, L. C. (2017). Non-CNS pathogenic origin of Parkinson's disease. J. Neurol. 264, 2027-2030.

Chouhan, A. K., Guo, C., Hsieh, Y. C., Ye, H., Senturk, M., Zuo, Z., et al. (2016). Uncoupling neuronal death and dysfunction in Drosophila models of neurodegenerative disease. Acta Neuropathol. Commun. 4:62.

Chung, H. K., Ho, H. A., Perez-Acuna, D., and Lee, S. J. (2019). Modeling alphasynuclein propagation with preformed fibril injections. J. Mov. Disord. 12, 139-151. doi: 10.14802/jmd.19046

Creel, D. J. (1995). "Clinical electrophysiology," in Webvision: The Organization of the Retina and Visual System, eds H. Kolb, E. Fernandez, and R. Nelson (Salt Lake City, UT: University of Utah Health Sciences Center).

Cubo, E., Tedejo, R. P., Rodriguez Mendez, V., Lopez Pena, M. J., and Trejo Gabriel, Y. G. J. M. (2010). Retina thickness in Parkinson's disease and essential tremor. Mov. Disord. 25, 2461-2462. doi: 10.1002/mds.23215

Cuenca, N., Herrero, M. T., Angulo, A., de Juan, E., Martinez-Navarrete, G. C., Lopez, S., et al. (2005). Morphological impairments in retinal neurons of the scotopic visual pathway in a monkey model of Parkinson's disease. J. Comp. Neurol. 493, 261-273. doi: 10.1002/cne.20761

Davis, G. C., Williams, A. C., Markey, S. P., Ebert, M. H., Caine, E. D., Reichert, C. M., et al. (1979). Chronic Parkinsonism secondary to intravenous injection of meperidine analogues. Psychiatry Res. 1, 249-254.

de Lau, L. M., and Breteler, M. M. (2006). Epidemiology of Parkinson's disease. Lancet Neurol. 5, 525-535.

Demb, J. B., and Singer, J. H. (2015). Functional circuitry of the retina. Annu. Rev. Vis. Sci. 1, 263-289.

Deng, H., Wang, P., and Jankovic, J. (2018). The genetics of Parkinson disease. Ageing Res. Rev. 42, 72-85. doi: 10.1016/j.arr.2017.12.007

Di Maio, R., Barrett, P. J., Hoffman, E. K., Barrett, C. W., Zharikov, A., Borah, A., et al. (2016). alpha-Synuclein binds to TOM20 and inhibits mitochondrial protein import in Parkinson's disease. Sci. Transl. Med. 8:342ra378. doi: 10. 1126/scitranslmed.aaf3634

Diederich, N. J., Goetz, C. G., and Stebbins, G. T. (2005). Repeated visual hallucinations in Parkinson's disease as disturbed external/internal perceptions: focused review and a new integrative model. Mov. Disord. 20, 130-140. doi: 10.1002/mds. 20308

Diederich, N. J., Pieri, V., Hipp, G., Rufra, O., Blyth, S., and Vaillant, M. (2010). Discriminative power of different nonmotor signs in early Parkinson's disease. A case-control study. Mov. Disord. 25, 882-887. doi: 10.1002/mds. 22963

Diederich, N. J., Raman, R., Leurgans, S., and Goetz, C. G. (2002). Progressive worsening of spatial and chromatic processing deficits in Parkinson disease. Arch. Neurol. 59, 1249-1252. doi: 10.1001/archneur.59.8.1249

Dikic, I., and Bremm, A. (2014). DUBs counteract parkin for efficient mitophagy. EMBO J. 33, 2442-2443. doi: 10.15252/embj.201490101
Dowling, J. E., and Ehinger, B. (1975). Synaptic organization of the aminecontaining interplexiform cells of the goldfish and Cebus monkey retinas. Science 188, 270-273. doi: 10.1126/science.804181

Edelstyn, N. M., Mayes, A. R., and Ellis, S. J. (2014). Damage to the dorsomedial thalamic nucleus, central lateral intralaminar thalamic nucleus, and midline thalamic nuclei on the right-side impair executive function and attention under conditions of high demand but not low demand. Neurocase 20, 121-132. doi: 10.1080/13554794.2012.713497

Ekker, M. S., Janssen, S., Seppi, K., Poewe, W., de Vries, N. M., Theelen, T., et al. (2017). Ocular and visual disorders in Parkinson's disease: common but frequently overlooked. Parkinsonism Relat. Disord. 40, 1-10. doi: 10.1016/j. parkreldis.2017.02.014

Eschbach, J., von Einem, B., Muller, K., Bayer, H., Scheffold, A., Morrison, B. E., et al. (2015). Mutual exacerbation of peroxisome proliferator-activated receptor gamma coactivator 1alpha deregulation and alpha-synuclein oligomerization. Ann. Neurol. 77, 15-32. doi: 10.1002/ana.24294

Esteve-Rudd, J., Fernandez-Sanchez, L., Lax, P., De Juan, E., Martin-Nieto, J., and Cuenca, N. (2011). Rotenone induces degeneration of photoreceptors and impairs the dopaminergic system in the rat retina. Neurobiol. Dis. 44, 102-115. doi: 10.1016/j.nbd.2011.06.009

Exner, N., Lutz, A. K., Haass, C., and Winklhofer, K. F. (2012). Mitochondrial dysfunction in Parkinson's disease: molecular mechanisms and pathophysiological consequences. EMBO J. 31, 3038-3062. doi: 10.1038/emboj.2012.170

Feigenspan, A., Gustincich, S., Bean, B. P., and Raviola, E. (1998). Spontaneous activity of solitary dopaminergic cells of the retina. J. Neurosci. 18, 6776-6789.

Fenelon, G., Mahieux, F., Huon, R., and Ziegler, M. (2000). Hallucinations in Parkinson's disease: prevalence, phenomenology and risk factors. Brain 123(Pt 4), 733-745. doi: 10.1093/brain/123.4.733

Ghilardi, M. F., Chung, E., Bodis-Wollner, I., Dvorzniak, M., Glover, A., and Onofrj, M. (1988). Systemic 1-methyl,4-phenyl,1-2-3-6-tetrahydropyridine (MPTP) administration decreases retinal dopamine content in primates. Life Sci. 43, 255-262.

Ghilardi, M. F., Marx, M. S., Bodis-Wollner, I., Camras, C. B., and Glover, A. A. (1989). The effect of intraocular 6-hydroxydopamine on retinal processing of primates. Ann. Neurol. 25, 357-364. doi: 10.1002/ana.410250407

Giannoccaro, M. P., La Morgia, C., Rizzo, G., and Carelli, V. (2017). Mitochondrial DNA and primary mitochondrial dysfunction in Parkinson's disease. Mov. Disord. 32, 346-363. doi: 10.1002/mds.26966

Giordano, N., Iemolo, A., Mancini, M., Cacace, F., De Risi, M., Latagliata, E. C., et al. (2018). Motor learning and metaplasticity in striatal neurons: relevance for Parkinson's disease. Brain 141, 505-520. doi: 10.1093/brain/awx351

Gottlob, I., Schneider, E., Heider, W., and Skrandies, W. (1987). Alteration of visual evoked potentials and electroretinograms in Parkinson's disease. Electroencephalogr. Clin. Neurophysiol. 66, 349-357.

Gullett, J. M., Price, C. C., Nguyen, P., Okun, M. S., Bauer, R. M., and Bowers, D. (2013). Reliability of three Benton judgment of line orientation short forms in idiopathic Parkinson's disease. Clin. Neuropsychol. 27, 1167-1178. doi: 10.1080/ 13854046.2013.827744

Guo, L., Normando, E. M., Shah, P. A., De Groef, L., and Cordeiro, M. F. (2018). Oculo-visual abnormalities in Parkinson's disease: possible value as biomarkers. Mov. Disord. 33, 1390-1406. doi: 10.1002/mds.27454

Gustincich, S., Feigenspan, A., Sieghart, W., and Raviola, E. (1999). Composition of the GABA(A) receptors of retinal dopaminergic neurons. J. Neurosci. 19, $7812-7822$.

Gustincich, S., Feigenspan, A., Wu, D. K., Koopman, L. J., and Raviola, E. (1997). Control of dopamine release in the retina: a transgenic approach to neural networks. Neuron 18, 723-736. doi: 10.1016/s0896-6273(00)80313-x

Harnois, C., and Di Paolo, T. (1990). Decreased dopamine in the retinas of patients with Parkinson's disease. Invest. Ophthalmol. Vis. Sci. 31, 24732475 .

Haug, B. A., Kolle, R. U., Trenkwalder, C., Oertel, W. H., and Paulus, W. (1995). Predominant affection of the blue cone pathway in Parkinson's disease. Brain 118(Pt 3), 771-778. doi: 10.1093/brain/118.3.771

Haug, B. A., Trenkwalder, C., Arden, G. B., Oertel, W. H., and Paulus, W. (1994). Visual thresholds to low-contrast pattern displacement, color contrast, and luminance contrast stimuli in Parkinson's disease. Mov. Disord. 9, 563-570. doi: $10.1002 / \mathrm{mds} .870090510$ 
He, S. B., Liu, C. Y., Chen, L. D., Ye, Z. N., Zhang, Y. P., Tang, W. G., et al. (2018). Meta-analysis of visual evoked potential and Parkinson's disease. Parkinsons Dis. 2018:3201308. doi: 10.1155/2018/3201308

Himmelberg, M. M., West, R. J. H., Elliott, C. J. H., and Wade, A. R. (2018), Abnormal visual gain control and excitotoxicity in early-onset Parkinson's disease Drosophila models. J. Neurophysiol. 119, 957-970. doi: 10.1152/jn. 00681.2017

Hindle, S., Afsari, F., Stark, M., Middleton, C. A., Evans, G. J., Sweeney, S. T., et al. (2013). Dopaminergic expression of the Parkinsonian gene LRRK2-G2019S leads to non-autonomous visual neurodegeneration, accelerated by increased neural demands for energy. Hum. Mol. Genet. 22, 2129-2140. doi: 10.1093/ hmg/ddt061

Ho, C. Y., Troncoso, J. C., Knox, D., Stark, W., and Eberhart, C. G. (2014). Betaamyloid, phospho-tau and alpha-synuclein deposits similar to those in the brain are not identified in the eyes of Alzheimer's and Parkinson's disease patients. Brain Pathol. 24, 25-32. doi: 10.1111/bpa.12070

Holroyd, S., Currie, L., and Wooten, G. F. (2001). Prospective study of hallucinations and delusions in Parkinson's disease. J. Neurol. Neurosurg. Psychiatry 70, 734-738. doi: 10.1136/jnnp.70.6.734

Hutton, J. T., Morris, J. L., and Elias, J. W. (1993). Levodopa improves spatial contrast sensitivity in Parkinson's disease. Arch. Neurol. 50, 721-724. doi: 10. 1001/archneur.1993.00540070041012

Ikeda, H., Head, G. M., and Ellis, C. J. (1994). Electrophysiological signs of retinal dopamine deficiency in recently diagnosed Parkinson's disease and a follow up study. Vision Res. 34, 2629-2638.

Indrieri, A., Carrella, S., Carotenuto, P., Banfi, S., and Franco, B. (2020). The pervasive role of the miR-181 family in development, neurodegeneration, and cancer. Int. J. Mol. Sci. 21:2092. doi: 10.3390/ijms 21062092

Indrieri, A., Carrella, S., Romano, A., Spaziano, A., Marrocco, E., FernandezVizarra, E., et al. (2019). miR-181a/b downregulation exerts a protective action on mitochondrial disease models. EMBO Mol. Med. 11:e8734. doi: 10.15252/ emmm.201708734

Inzelberg, R., Ramirez, J. A., Nisipeanu, P., and Ophir, A. (2004). Retinal nerve fiber layer thinning in Parkinson disease. Vision Res. 44, 2793-2797. doi: 10.1016/j. visres.2004.06.009

Iranzo, A., Tolosa, E., Gelpi, E., Molinuevo, J. L., Valldeoriola, F., Serradell, M., et al. (2013). Neurodegenerative disease status and post-mortem pathology in idiopathic rapid-eye-movement sleep behaviour disorder: an observational cohort study. Lancet Neurol. 12, 443-453.

Iwai, A., Masliah, E., Yoshimoto, M., Ge, N., Flanagan, L., de Silva, H. A., et al. (1995). The precursor protein of non-A beta component of Alzheimer's disease amyloid is a presynaptic protein of the central nervous system. Neuron 14, 467-475. doi: 10.1016/0896-6273(95)90302-x

Jackson, C. R., Ruan, G. X., Aseem, F., Abey, J., Gamble, K., Stanwood, G., et al. (2012). Retinal dopamine mediates multiple dimensions of light-adapted vision. J. Neurosci. 32, 9359-9368. doi: 10.1523/JNEUROSCI.0711-12.2012

Janezic, S., Threlfell, S., Dodson, P. D., Dowie, M. J., Taylor, T. N., Potgieter, D., et al. (2013). Deficits in dopaminergic transmission precede neuron loss and dysfunction in a new Parkinson model. Proc. Natl. Acad. Sci. U.S.A. 110, E4016-E4025. doi: 10.1073/pnas.1309143110

Javitch, J. A., D'Amato, R. J., Strittmatter, S. M., and Snyder, S. H. (1985). Parkinsonism-inducing neurotoxin, N-methyl-4-phenyl-1,2,3,6 tetrahydropyridine: uptake of the metabolite N-methyl-4-phenylpyridine by dopamine neurons explains selective toxicity. Proc. Natl. Acad. Sci. U.S.A. 82, 2173-2177. doi: 10.1073/pnas.82.7.2173

Jenner, P. (2001). Parkinson's disease, pesticides and mitochondrial dysfunction. Trends Neurosci. 24, 245-247.

Jones, R. D., Donaldson, I. M., and Timmings, P. L. (1992). Impairment of highcontrast visual acuity in Parkinson's disease. Mov. Disord. 7, 232-238. doi: $10.1002 / \mathrm{mds} .870070308$

Kahle, P. J., Neumann, M., Ozmen, L., Muller, V., Jacobsen, H., Schindzielorz, A., et al. (2000). Subcellular localization of wild-type and Parkinson's diseaseassociated mutant alpha -synuclein in human and transgenic mouse brain. J. Neurosci. 20, 6365-6373.

Kalia, L. V., and Lang, A. E. (2015). Parkinson's disease. Lancet 386, 896-912.

Kamp, F., Exner, N., Lutz, A. K., Wender, N., Hegermann, J., Brunner, B., et al. (2010). Inhibition of mitochondrial fusion by alpha-synuclein is rescued by PINK1, Parkin and DJ-1. EMBO J. 29, 3571-3589. doi: 10.1038/emboj.2010.223
Kirbas, S., Turkyilmaz, K., Tufekci, A., and Durmus, M. (2013). Retinal nerve fiber layer thickness in Parkinson disease. J. Neuroophthalmol. 33, 62-65. doi: 10.1097/WNO.0b013e3182701745

Koentjoro, B., Park, J. S., and Sue, C. M. (2017). Nix restores mitophagy and mitochondrial function to protect against PINK1/Parkin-related Parkinson's disease. Sci. Rep. 7:44373. doi: 10.1038/srep44373

Kupersmith, M. J., Shakin, E., Siegel, I. M., and Lieberman, A. (1982). Visual system abnormalities in patients with Parkinson's disease. Arch. Neurol. 39, 284-286. doi: 10.1001/archneur.1982.00510170026007

La Morgia, C., Barboni, P., Rizzo, G., Carbonelli, M., Savini, G., Scaglione, C., et al. (2013). Loss of temporal retinal nerve fibers in Parkinson disease: a mitochondrial pattern? Eur. J. Neurol. 20, 198-201. doi: 10.1111/j.1468-1331. 2012.03701.x

Langston, J. W., Ballard, P., Tetrud, J. W., and Irwin, I. (1983). Chronic Parkinsonism in humans due to a product of meperidine-analog synthesis. Science 219, 979-980. doi: 10.1126/science.6823561

Lee, J. Y., Ahn, J., Kim, T. W., and Jeon, B. S. (2014a). Optical coherence tomography in Parkinson's disease: is the retina a biomarker? J. Parkinsons Dis. 4, 197-204. doi: 10.3233/JPD- 130306

Lee, J. Y., Kim, J. M., Ahn, J., Kim, H. J., Jeon, B. S., and Kim, T. W. (2014b). Retinal nerve fiber layer thickness and visual hallucinations in Parkinson's Disease. Mov. Disord. 29, 61-67. doi: 10.1002/mds.25543

Leger, F., Fernagut, P. O., Canron, M. H., Leoni, S., Vital, C., Tison, F., et al. (2011). Protein aggregation in the aging retina. J. Neuropathol. Exp. Neurol. 70, 63-68. doi: 10.1097/NEN.0b013e31820376cc

Lin, T. P., Rigby, H., Adler, J. S., Hentz, J. G., Balcer, L. J., Galetta, S. L., et al. (2015). Abnormal visual contrast acuity in Parkinson's disease. J. Parkinsons Dis. 5, 125-130. doi: 10.3233/JPD- 140470

Liu, C., Zhang, Y., Tang, W., Wang, B., Wang, B., and He, S. (2017). Evoked potential changes in patients with Parkinson's disease. Brain Behav. 7:e00703. doi: $10.1002 / b r b 3.703$

Lundblad, M., Decressac, M., Mattsson, B., and Bjorklund, A. (2012). Impaired neurotransmission caused by overexpression of alpha-synuclein in nigral dopamine neurons. Proc. Natl. Acad. Sci. U.S.A. 109, 3213-3219. doi: 10.1073/ pnas. 1200575109

Mahlknecht, P., Seppi, K., and Poewe, W. (2015). The concept of prodromal Parkinson's disease. J. Parkinsons Dis. 5, 681-697. doi: 10.3233/JPD-150685

Mammadova, N., Summers, C. M., Kokemuller, R. D., He, Q., Ding, S., Baron, T., et al. (2019). Accelerated accumulation of retinal alpha-synuclein (pSer129) and tau, neuroinflammation, and autophagic dysregulation in a seeded mouse model of Parkinson's disease. Neurobiol. Dis. 121, 1-16. doi: 10.1016/j.nbd.2018. 09.013

Maresca, A., la Morgia, C., Caporali, L., Valentino, M. L., and Carelli, V. (2013). The optic nerve: a "mito-window" on mitochondrial neurodegeneration. Mol. Cell. Neurosci. 55, 62-76. doi: 10.1016/j.mcn.2012.08.004

Marras, C., Schule, B., Munhoz, R. P., Rogaeva, E., Langston, J. W., Kasten, M., et al. (2011). Phenotype in parkinsonian and nonparkinsonian LRRK2 G2019S mutation carriers. Neurology 77, 325-333. doi: 10.1212/WNL. 0b013e318227042d

Marrocco, E., Indrieri, A., Esposito, F., Tarallo, V., Carboncino, A., Alvino, F., et al. (2020). $\alpha$-synuclein overexpression in the retina leads to vision impairment and degeneration of dopaminergic amacrine cells. Sci. Rep. 10:9619.

Martin, L. J., Pan, Y., Price, A. C., Sterling, W., Copeland, N. G., Jenkins, N. A., et al. (2006). Parkinson's disease alpha-synuclein transgenic mice develop neuronal mitochondrial degeneration and cell death. J. Neurosci. 26, 41-50. doi: 10.1523/ JNEUROSCI.4308-05.2006

Martinez-Navarrete, G. C., Martin-Nieto, J., Esteve-Rudd, J., Angulo, A., and Cuenca, N. (2007). Alpha synuclein gene expression profile in the retina of vertebrates. Mol. Vis. 13, 949-961.

Masliah, E., Rockenstein, E., Veinbergs, I., Mallory, M., Hashimoto, M., Takeda, A., et al. (2000). Dopaminergic loss and inclusion body formation in alphasynuclein mice: implications for neurodegenerative disorders. Science 287, 1265-1269. doi: 10.1126/science.287.5456.1265

Matlach, J., Wagner, M., Malzahn, U., Schmidtmann, I., Steigerwald, F., Musacchio, T., et al. (2018). Retinal changes in Parkinson's disease and glaucoma. Parkinsonism Relat. Disord. 56, 41-46. doi: 10.1016/j.parkreldis.2018.06.016

Matsui, H., Udaka, F., Tamura, A., Oda, M., Kubori, T., Nishinaka, K., et al. (2006). Impaired visual acuity as a risk factor for visual hallucinations in 
Parkinson's disease. J. Geriatr. Psychiatry Neurol. 19, 36-40. doi: 10.1177/ 0891988705284739

May, C. A., Nakamura, K., Fujiyama, F., and Yanagawa, Y. (2008). Quantification and characterization of GABA-ergic amacrine cells in the retina of GAD67-GFP knock-in mice. Acta Ophthalmol. 86, 395-400. doi: 10.1111/j.1600-0420.2007. 01054.x

McMahon, D. G., Iuvone, P. M., and Tosini, G. (2014). Circadian organization of the mammalian retina: from gene regulation to physiology and diseases. Prog. Retin. Eye Res. 39, 58-76. doi: 10.1016/j.preteyeres.2013.12.001

Meng, T., Zheng, Z. H., Liu, T. T., and Lin, L. (2012). Contralateral retinal dopamine decrease and melatonin increase in progression of hemiparkinsonium rat. Neurochem. Res. 37, 1050-1056.

Miri, S., Glazman, S., Mylin, L., and Bodis-Wollner, I. (2016). A combination of retinal morphology and visual electrophysiology testing increases diagnostic yield in Parkinson's disease. Parkinsonism Relat. Disord. 22(Suppl. 1), S134S137. doi: 10.1016/j.parkreldis.2015.09.015

Montse, A., Pere, V., Carme, J., Francesc, V., and Eduardo, T. (2001). Visuospatial deficits in Parkinson's disease assessed by judgment of line orientation test: error analyses and practice effects. J. Clin. Exp. Neuropsychol. 23, 592-598. doi: 10.1076/jcen.23.5.592.1248

Moreno-Ramos, T., Benito-Leon, J., Villarejo, A., and Bermejo-Pareja, F. (2013). Retinal nerve fiber layer thinning in dementia associated with Parkinson's disease, dementia with Lewy bodies, and Alzheimer's disease. J. Alzheimers Dis. 34, 659-664. doi: 10.3233/JAD- 121975

Moschos, M. M., Tagaris, G., Markopoulos, I., Margetis, I., Tsapakis, S., Kanakis, M., et al. (2011). Morphologic changes and functional retinal impairment in patients with Parkinson disease without visual loss. Eur. J. Ophthalmol. 21, 24-29. doi: 10.5301/ejo.2010.1318

Muller, T., Woitalla, D., Peters, S., Kohla, K., and Przuntek, H. (2002). Progress of visual dysfunction in Parkinson's disease. Acta Neurol. Scand. 105, 256-260. doi: 10.1034/j.1600-0404.2002.1o154.x

Nakamura, K., Nemani, V. M., Azarbal, F., Skibinski, G., Levy, J. M., Egami, K., et al. (2011). Direct membrane association drives mitochondrial fission by the Parkinson disease-associated protein alpha-synuclein. J. Biol. Chem. 286, 20710-20726. doi: 10.1074/jbc.M110.213538

Nemani, V. M., Lu, W., Berge, V., Nakamura, K., Onoa, B., Lee, M. K., et al. (2010), Increased expression of alpha-synuclein reduces neurotransmitter release by inhibiting synaptic vesicle reclustering after endocytosis. Neuron 65, 66-79. doi: $10.1016 /$ j.neuron.2009.12.023

Nguyen-Legros, J. (1988). Functional neuroarchitecture of the retina: hypothesis on the dysfunction of retinal dopaminergic circuitry in Parkinson's disease. Surg. Radiol. Anat. 10, 137-144. doi: 10.1007/BF02307822

Normando, E. M., Davis, B. M., De Groef, L., Nizari, S., Turner, L. A., Ravindran, N., et al. (2016). The retina as an early biomarker of neurodegeneration in a rotenone-induced model of Parkinson's disease: evidence for a neuroprotective effect of rosiglitazone in the eye and brain. Acta Neuropathol. Commun. 4:86. doi: 10.1186/s40478-016-0346-z

Nowacka, B., Lubinski, W., Honczarenko, K., Potemkowski, A., and Safranow, K. (2015). Bioelectrical function and structural assessment of the retina in patients with early stages of Parkinson's disease (PD). Doc. Ophthalmol. 131, 95-104.

Ordonez, D. G., Lee, M. K., and Feany, M. B. (2018). alpha-synuclein induces mitochondrial dysfunction through spectrin and the actin cytoskeleton. Neuron 97, 108-124.e6. doi: 10.1016/j.neuron.2017.11.036

Ortuno-Lizaran, I., Beach, T. G., Serrano, G. E., Walker, D. G., Adler, C. H., and Cuenca, N. (2018). Phosphorylated alpha-synuclein in the retina is a biomarker of Parkinson's disease pathology severity. Mov. Disord. 33, 1315-1324. doi: $10.1002 / \mathrm{mds} .27392$

Ortuno-Lizaran, I., Sanchez-Saez, X., Lax, P., Serrano, G. E., Beach, T. G., Adler, C. H., et al. (2020). Dopaminergic retinal cell loss and visual dysfunction in Parkinson's disease. Ann. Neurol. doi: 10.1002/ana.25897 [Epub ahead of print].

Oueslati, A. (2016). Implication of alpha-synuclein phosphorylation at S129 in synucleinopathies: what have we learned in the last decade? J. Parkinsons Dis. 6, 39-51. doi: 10.3233/JPD- 160779

Pieri, V., Diederich, N. J., Raman, R., and Goetz, C. G. (2000). Decreased color discrimination and contrast sensitivity in Parkinson's disease. J. Neurol. Sci. 172, 7-11. doi: 10.1016/s0022-510x(99)00204-x
Piro, A., Tagarelli, A., Nicoletti, G., Fletcher, R., and Quattrone, A. (2014). Color vision impairment in Parkinson's disease. J. Parkinsons Dis. 4, 317-319. doi: 10.3233/JPD- 140359

Polo, V., Satue, M., Rodrigo, M. J., Otin, S., Alarcia, R., Bambo, M. P., et al. (2016). Visual dysfunction and its correlation with retinal changes in patients with Parkinson's disease: an observational cross-sectional study. BMJ Open 6:e009658.

Possin, K. L. (2010). Visual spatial cognition in neurodegenerative disease. Neurocase 16, 466-487. doi: 10.1080/13554791003730600

Postuma, R. B., Aarsland, D., Barone, P., Burn, D. J., Hawkes, C. H., Oertel, W., et al. (2012). Identifying prodromal Parkinson's disease: pre-motor disorders in Parkinson's disease. Mov. Disord. 27, 617-626. doi: 10.1002/mds.24996

Postuma, R. B., Berg, D., Stern, M., Poewe, W., Olanow, C. W., Oertel, W., et al. (2015). MDS clinical diagnostic criteria for Parkinson's disease. Mov. Disord. 30, 1591-1601. doi: 10.1002/mds.26424

Postuma, R. B., Gagnon, J. F., Vendette, M., Desjardins, C., and Montplaisir, J. Y. (2011). Olfaction and color vision identify impending neurodegeneration in rapid eye movement sleep behavior disorder. Ann. Neurol. 69, 811-818. doi: 10.1002/ana.22282

Postuma, R. B., Lang, A. E., Massicotte-Marquez, J., and Montplaisir, J. (2006). Potential early markers of Parkinson disease in idiopathic REM sleep behavior disorder. Neurology 66, 845-851. doi: 10.1212/01.wnl.0000203648.80727.5b

Price, M. J., Feldman, R. G., Adelberg, D., and Kayne, H. (1992). Abnormalities in color vision and contrast sensitivity in Parkinson's disease. Neurology 42, 887-890. doi: 10.1212/wnl.42.4.887

Puopolo, M., Hochstetler, S. E., Gustincich, S., Wightman, R. M., and Raviola, E. (2001). Extrasynaptic release of dopamine in a retinal neuron: activity dependence and transmitter modulation. Neuron 30, 211-225.

Puschmann, A. (2017). New genes causing hereditary Parkinson's disease or Parkinsonism. Curr. Neurol. Neurosci. Rep. 17:66.

Ramsay, R. R., and Singer, T. P. (1986). Energy-dependent uptake of N-methyl4-phenylpyridinium, the neurotoxic metabolite of 1-methyl-4-phenyl-1,2,3,6tetrahydropyridine, by mitochondria. J. Biol. Chem. 261, 7585-7587.

Regan, D., and Neima, D. (1984). Low-contrast letter charts in early diabetic retinopathy, ocular hypertension, glaucoma, and Parkinson's disease. Br. J. Ophthalmol. 68, 885-889. doi: 10.1136/bjo.68.12.885

Ridder, A., Muller, M. L., Kotagal, V., Frey, K. A., Albin, R. L., and Bohnen, N. I. (2017). Impaired contrast sensitivity is associated with more severe cognitive impairment in Parkinson disease. Parkinsonism Relat. Disord. 34, 15-19. doi: 10.1016/j.parkreldis.2016.10.006

Rodriguez-Blazquez, C., Forjaz, M. J., Lizan, L., Paz, S., and Martinez-Martin, P. (2015). Estimating the direct and indirect costs associated with Parkinson's disease. Expert Rev. Pharmacoecon. Outcomes Res. 15, 889-911. doi: 10.1586/ 14737167.2015.1103184

Roy, S., and Field, G. D. (2019). Dopaminergic modulation of retinal processing from starlight to sunlight. J. Pharmacol. Sci. 140, 86-93. doi: 10.1016/j.jphs. 2019.03.006

Sartucci, F., and Porciatti, V. (2006). Visual-evoked potentials to onset of chromatic red-green and blue-yellow gratings in Parkinson's disease never treated with L-dopa. J. Clin. Neurophysiol. 23, 431-435. doi: 10.1097/01.wnp.0000216127. $53517.4 \mathrm{~d}$

Satue, M., Obis, J., Rodrigo, M. J., Otin, S., Fuertes, M. I., Vilades, E., et al. (2016). Optical coherence tomography as a biomarker for diagnosis, progression, and prognosis of neurodegenerative diseases. J. Ophthalmol. 2016:8503859. doi: 10. $1155 / 2016 / 8503859$

Savy, C., Moussafi, F., Durand, J., Yelnik, J., Simon, A., and Nguyen-Legros, J. (1995). Distribution and spatial geometry of dopamine interplexiform cells in the retina. II. External arborizations in the adult rat and monkey. J. Comp. Neurol. 355, 392-404. doi: 10.1002/cne.903550306

Schapira, A. H. (2008). Mitochondria in the aetiology and pathogenesis of Parkinson's disease. Lancet Neurol. 7, 97-109.

Schneider, J. S., Ault, M. E., and Anderson, D. W. (2014). Retinal pathology detected by optical coherence tomography in an animal model of Parkinson's disease. Mov. Disord. 29, 1547-1551. doi: 10.1002/mds.25974

Seeman, P., and Van Tol, H. H. (1994). Dopamine receptor pharmacology. Trends Pharmacol. Sci. 15, 264-270. 
Shrier, E. M., Adam, C. R., Spund, B., Glazman, S., and Bodis-Wollner, I. (2012). Interocular asymmetry of foveal thickness in Parkinson disease. J. Ophthalmol. 2012:728457. doi: 10.1155/2012/728457

Siderowf, A., and Lang, A. E. (2012). Premotor Parkinson's disease: concepts and definitions. Mov. Disord. 27, 608-616. doi: 10.1002/mds.24954

Silva, M. F., Faria, P., Regateiro, F. S., Forjaz, V., Januario, C., Freire, A., et al. (2005). Independent patterns of damage within magno-, parvo- and koniocellular pathways in Parkinson's disease. Brain 128(Pt 10), 2260-2271. doi: 10.1093/brain/awh581

Spillantini, M. G., Schmidt, M. L., Lee, V. M., Trojanowski, J. Q., Jakes, R., and Goedert, M. (1997). Alpha-synuclein in Lewy bodies. Nature 388, 839-840. doi: $10.1038 / 42166$

Spund, B., Ding, Y., Liu, T., Selesnick, I., Glazman, S., Shrier, E. M., et al. (2013). Remodeling of the fovea in Parkinson disease. J. Neural Transm. 120, 745-753.

Stanzione, P., Pierantozzi, M., Semprini, R., Tagliati, M., Traversa, R., Peppe, A., et al. (1995). Increasing doses of l-sulpiride reveal dose- and spatial frequencydependent effects of D2 selective blockade in the human electroretinogram. Vision Res. 35, 2659-2664. doi: 10.1016/0042-6989(95)00037-z

Stenc Bradvica, I., Bradvica, M., Matic, S., and Reisz-Majic, P. (2015). Visual dysfunction in patients with Parkinson's disease and essential tremor. Neurol. Sci. 36, 257-262.

Tagliati, M., Bodis-Wollner, I., Kovanecz, I., and Stanzione, P. (1994). Spatial frequency tuning of the monkey pattern ERG depends on D2 receptor-linked action of dopamine. Vision Res. 34, 2051-2057.

Takatsuna, Y., Adachi-Usami, E., Ino, H., and Chiba, T. (1992). [Effects of MPTP on the mouse retina]. Nippon Ganka Gakkai Zasshi 96, 767-775.

Tartaglione, A., Oneto, A., Bandini, F., and Favale, E. (1987). Visual evoked potentials and pattern electroretinograms in Parkinson's disease and control subjects. J. Neurol. Neurosurg. Psychiatry 50, 1243-1244. doi: 10.1136/jnnp.50. 9.1243

Tatton, W. G., Kwan, M. M., Verrier, M. C., Seniuk, N. A., and Theriault, E. (1990). MPTP produces reversible disappearance of tyrosine hydroxylase-containing retinal amacrine cells. Brain Res. 527, 21-31. doi: 10.1016/0006-8993(90)9 1056-m

Tsironi, E. E., Dastiridou, A., Katsanos, A., Dardiotis, E., Veliki, S., Patramani, G., et al. (2012). Perimetric and retinal nerve fiber layer findings in patients with Parkinson's disease. BMC Ophthalmol. 12:54. doi: 10.1186/1471-2415-12-54

Turcano, P., Chen, J. J., Bureau, B. L., and Savica, R. (2019). Early ophthalmologic features of Parkinson's disease: a review of preceding clinical and diagnostic markers. J. Neurol. 266, 2103-2111.

Uc, E. Y., Rizzo, M., Anderson, S. W., Qian, S., Rodnitzky, R. L., and Dawson, J. D. (2005). Visual dysfunction in Parkinson disease without dementia. Neurology 65, 1907-1913. doi: 10.1212/01.wnl.0000191565.11065.11

Vasquez, V., Mitra, J., Wang, H., Hegde, P. M., Rao, K. S., and Hegde, M. L. (2020). A multi-faceted genotoxic network of alpha-synuclein in the nucleus and mitochondria of dopaminergic neurons in Parkinson's disease: emerging concepts and challenges. Prog. Neurobiol. 185:101729. doi: 10.1016/j.pneurobio. 2019.101729

Veruki, M. L., and Wassle, H. (1996). Immunohistochemical localization of dopamine D1 receptors in rat retina. Eur. J. Neurosci. 8, 2286-2297. doi: 10. 1111/j.1460-9568.1996.tb01192.x
Vesela, O., Ruzicka, E., Jech, R., Roth, J., Stepankova, K., Mecir, P., et al. (2001). Colour discrimination impairment is not a reliable early marker of Parkinson's disease. J. Neurol. 248, 975-978. doi: 10.1007/s004150170051

Veys, L., Vandenabeele, M., Ortuno-Lizaran, I., Baekelandt, V., Cuenca, N., Moons, L., et al. (2019). Retinal alpha-synuclein deposits in Parkinson's disease patients and animal models. Acta Neuropathol. 137, 379-395. doi: 10.1007/s00401-01801956-Z

Weil, R. S., Schrag, A. E., Warren, J. D., Crutch, S. J., Lees, A. J., and Morris, H. R. (2016). Visual dysfunction in Parkinson's disease. Brain 139, 2827-2843. doi: 10.1093/brain/aww175

White, K. E., Davies, V. J., Hogan, V. E., Piechota, M. J., Nichols, P. P., Turnbull, D. M., et al. (2009). OPA1 deficiency associated with increased autophagy in retinal ganglion cells in a murine model of dominant optic atrophy. Invest. Ophthalmol. Vis. Sci. 50, 2567-2571.

Whitworth, A. J., and Pallanck, L. J. (2009). The PINK1/Parkin pathway: a mitochondrial quality control system? J. Bioenerg. Biomembr. 41, 499-503.

Winograd-Gurvich, C., Georgiou-Karistianis, N., Fitzgerald, P. B., Millist, L., and White, O. B. (2006). Self-paced saccades and saccades to oddball targets in Parkinson's disease. Brain Res. 1106, 134-141. doi: 10.1016/j.brainres.2006.05. 103

Witkovsky, P. (2004). Dopamine and retinal function. Doc. Ophthalmol. 108, 17-40. doi: 10.1023/b:doop.0000019487.88486.0a

Wong, Y. C., and Krainc, D. (2017). alpha-synuclein toxicity in neurodegeneration: mechanism and therapeutic strategies. Nat. Med. 23, 1-13. doi: 10.1038/nm. 4269

Yavas, G. F., Yilmaz, O., Kusbeci, T., and Ozturk, F. (2007). The effect of levodopa and dopamine agonists on optic nerve head in Parkinson disease. Eur. J. Ophthalmol. 17, 812-816. doi: 10.1177/1120672107017 00520

Yu-Wai-Man, P., Griffiths, P. G., and Chinnery, P. F. (2011). Mitochondrial optic neuropathies - disease mechanisms and therapeutic strategies. Prog. Retin. Eye Res. 30, 81-114. doi: 10.1016/j.preteyeres.2010.11.002

Yu-Wai-Man, P., Votruba, M., Burte, F., La Morgia, C., Barboni, P., and Carelli, V. (2016). A neurodegenerative perspective on mitochondrial optic neuropathies. Acta Neuropathol. 132, 789-806.

Zheng, B., Liao, Z., Locascio, J. J., Lesniak, K. A., Roderick, S. S., Watt, M. L., et al. (2010). PGC-1alpha, a potential therapeutic target for early intervention in Parkinson's disease. Sci. Transl. Med. 2:52ra73. doi: 10.1126/scitranslmed. 3001059

Conflict of Interest: The authors declare that this study received funding from Fondazione Roche. The funder was not involved in the study design, collection, analysis, interpretation of data, the writing of this article or the decision to submit it for publication.

Copyright (c) 2020 Indrieri, Pizzarelli, Franco and De Leonibus. This is an open-access article distributed under the terms of the Creative Commons Attribution License (CC BY). The use, distribution or reproduction in other forums is permitted, provided the original author(s) and the copyright owner(s) are credited and that the original publication in this journal is cited, in accordance with accepted academic practice. No use, distribution or reproduction is permitted which does not comply with these terms. 